\title{
Solid-State Kinetic Investigations of Nonisothermal Reduction of Iron Species Supported on SBA-15
}

\author{
N. S. Genz, ${ }^{1}$ D. Baabe, ${ }^{2}$ and T. Ressler ${ }^{1}$ \\ ${ }^{1}$ Institut für Chemie, Technische Universität Berlin, Straße des 17. Juni 135, 10623 Berlin, Germany \\ ${ }^{2}$ Institut für Anorganische und Analytische Chemie, Technische Universität Braunschweig, Hagenring 30, \\ 38106 Braunschweig, Germany \\ Correspondence should be addressed to T. Ressler; thorsten.ressler@tu-berlin.de
}

Received 8 May 2017; Revised 13 September 2017; Accepted 26 September 2017; Published 1 November 2017

Academic Editor: Adam Voelkel

Copyright (C) 2017 N. S. Genz et al. This is an open access article distributed under the Creative Commons Attribution License, which permits unrestricted use, distribution, and reproduction in any medium, provided the original work is properly cited.

\begin{abstract}
Iron oxide catalysts supported on nanostructured silica SBA-15 were synthesized with various iron loadings using two different precursors. Structural characterization of the as-prepared $\mathrm{Fe}_{x} \mathrm{O}_{y} / \mathrm{SBA}-15$ samples was performed by nitrogen physisorption, X-ray diffraction, DR-UV-Vis spectroscopy, and Mössbauer spectroscopy. An increasing size of the resulting iron species correlated with an increasing iron loading. Significantly smaller iron species were obtained from (Fe(III), $\mathrm{NH}_{4}$ )-citrate precursors compared to $\mathrm{Fe}(\mathrm{III})$-nitrate precursors. Moreover, smaller iron species resulted in a smoother surface of the support material. Temperatureprogrammed reduction (TPR) of the $\mathrm{Fe}_{x} \mathrm{O}_{y} / \mathrm{SBA}-15$ samples with $\mathrm{H}_{2}$ revealed better reducibility of the samples originating from $\mathrm{Fe}(\mathrm{III})$-nitrate precursors. Varying the iron loading led to a change in reduction mechanism. TPR traces were analyzed by modelindependent Kissinger method, Ozawa, Flynn, and Wall (OFW) method, and model-dependent Coats-Redfern method. JMAK kinetic analysis afforded a one-dimensional reduction process for the $\mathrm{Fe}_{x} \mathrm{O}_{y} / \mathrm{SBA}-15$ samples. The Kissinger method yielded the lowest apparent activation energy for the lowest loaded citrate sample $\left(E_{a} \approx 39 \mathrm{~kJ} / \mathrm{mol}\right)$. Conversely, the lowest loaded nitrate sample possessed the highest apparent activation energy $\left(E_{a} \approx 88 \mathrm{~kJ} / \mathrm{mol}\right)$. For samples obtained from Fe(III)-nitrate precursors, $E_{a}$ decreased with increasing iron loading. Apparent activation energies from model-independent analysis methods agreed well with those from model-dependent methods. Nucleation as rate-determining step in the reduction of the iron oxide species was consistent with the Mampel solid-state reaction model.
\end{abstract}

\section{Introduction}

Metal oxide catalysts with complex chemical compositions are often employed in selective oxidation reactions [1]. Not only oxygen mobility and lattice diffusion but also redox properties of the metal oxide catalyst significantly influence performance in selective oxidation. Therefore, understanding reduction and reoxidation kinetics is a fundamental starting point for deducing reliable structure-activity correlations. Iron-containing catalysts are active in nitrogen oxides removal, Friedel-Crafts reactions, Fischer-Tropsch synthesis, catalytic methane decomposition, and selective oxidation reactions [1-7]. Moreover, redox promotors such as $\mathrm{Fe}^{2+} / \mathrm{Fe}^{3+}$ are used to improve redox properties of selective oxidation catalysts $[1,8,9]$.

In catalysis research, more often than not, revealing reliable structure-activity correlations requires reducing chemical and structural complexity of metal oxide catalysts. Moreover, catalytic reactions occur on the surface of the catalysts, while the surface structure may differ significantly from that of the bulk. Therefore, dispersing metal oxides on well-defined support materials may result in suitable model systems. Various synthesis procedures have been used for dispersing active iron oxide species on suitable support materials. However, achieving well-dispersed and small or even isolated iron species on the support remains challenging [3]. Nanostructured silica materials, such as SBA-15, represent suitable support materials for metal oxide catalysts [10]. Furthermore, the size of the resulting species can be influenced by using various precursors for synthesis [3].

Evolution of structure and function of heterogeneous catalysts are frequently determined under nonisothermal conditions. Hence, additional solid-state kinetic analysis of experimental data measured under these conditions may be 
helpful in corroborating structure-activity correlations [1114]. Experimental measurements for solid-state kinetic analysis can be performed under either isothermal or nonisothermal reaction conditions. Dependent on reaction conditions, fundamentally different analysis methods are required. Moreover, in contrast to isothermal conditions, solid-state kinetic investigations under nonisothermal conditions require a more complex mathematical analysis. In this work, we aimed at establishing solid-state kinetic analysis procedures for treating conventional temperature-programmed reduction data. Although originally intended for analyzing data measured for bulk samples, these procedures are shown to be equally useful for treating data measured for supported oxide species.

For solid-state kinetic analysis of data measured under nonisothermal conditions, two approaches can be distinguished. First, solid-state kinetic data can be analyzed by model-independent Kissinger or isoconversional method of Ozawa, Flynn, and Wall (OFW). Whereas the Kissinger method yields one apparent activation energy of the ratedetermining step, the OFW method yields an evolution of apparent activation energy as function of reaction degree $\alpha$. Model-independent kinetic analysis is not based on any model assumptions; consequently the "kinetic triple" (apparent activation energy $E_{a}$, preexponential factor $A$ of the Arrhenius-type temperature-dependence of the rate constant, and suitable solid-state reaction model $g(\alpha)$ ) cannot be identified. Therefore, a second complementary approach to solid-state kinetic analysis is required. Model-dependent solid-state kinetic analysis employs several solid-state kinetic reaction models $g(\alpha)$. After identifying the suitable solidstate reaction model, the "kinetic triple" can be determined.

Here, iron oxide catalysts supported on SBA-15 as suitable model catalyst for selective oxidation were studied under various nonisothermal reaction conditions. Influence of iron loading and various precursors on structural and kinetic properties of the catalysts was investigated.

\section{Experimental}

2.1. Sample Preparation. Mesoporous silica SBA-15 was prepared according to Zhao et al. [10]. The surfactant, Pluronic ${ }^{\circledR}$ $\mathrm{P} 123$, was dissolved in a mixture of deionized water and $\mathrm{HCl}$ (37\%) and the reaction mixture was stirred at $308 \mathrm{~K}$ for $24 \mathrm{~h}$. Tetraethyl orthosilicate (TEOS) was added to the solution and the reaction mixture was stirred at $308 \mathrm{~K}$ for $24 \mathrm{~h}$ and then hydrothermally treated in pressure-resistant bottles at $388 \mathrm{~K}$ for $24 \mathrm{~h}$. The obtained white solid was filtered, washed with a mixture of deionized water and ethanol (20:1), air-dried, and calcined. Calcination was carried out in three steps: (I) $378 \mathrm{~K}$ for $135 \mathrm{~min}$, (II) $453 \mathrm{~K}$ for $3 \mathrm{~h}$, and (III) $873 \mathrm{~K}$ for $5 \mathrm{~h}$. The heating rate was kept at $1 \mathrm{~K} / \mathrm{min}$. Iron oxides supported on SBA-15 were prepared by incipient wetness technique. Therefore, an aqueous solution of ( $\mathrm{Fe}(\mathrm{III}), \mathrm{NH}_{4}$ )-citrate or $\mathrm{Fe}(\mathrm{III})$-nitrate was used. After drying in air for $24 \mathrm{~h}$, calcination was carried out at $723 \mathrm{~K}$ for $2 \mathrm{~h}$. According to the iron loading and the used precursor, samples were denoted as $2.5 \mathrm{wt} \% \mathrm{Fe} \_\mathrm{Citrate}$, 6.3 wt $\%$ Fe_Citrate, 10.7 wt $\%$ Fe_Citrate, 2.0 wt $\%$ Fe_Nitrate, $7.2 \mathrm{wt} \% \mathrm{Fe} \_$Nitrate, and $9.3 \mathrm{wt} \% \mathrm{Fe} \_$Nitrate.
Furthermore, a mechanical mixture of SBA-15 and crystalline $\alpha-\mathrm{Fe}_{2} \mathrm{O}_{3}(10.5 \mathrm{wt} \% \mathrm{Fe})$ was prepared and denoted as $\mathrm{Fe}_{2} \mathrm{O}_{3} / \mathrm{SBA}-15$.

2.2. Nitrogen Physisorption. Nitrogen adsorption/desorption isotherms were measured at $77 \mathrm{~K}$ using a BELSORP-mini II (BEL Japan, Inc.). Prior to measurements, the samples were pretreated under reduced pressure $\left(10^{-2} \mathrm{kPa}\right)$ at $368 \mathrm{~K}$ for $35 \mathrm{~min}$ and kept under the same pressure at $448 \mathrm{~K}$ for $15 \mathrm{~h}$ (BELPREP-vac II).

2.3. Transmission Electron Microscopy. Transmission electron microscopy (TEM) images were recorded on a FEI Tecnai $\mathrm{G}^{2} 20$ S-TWIN microscope equipped with a $\mathrm{LaB}_{6}$ cathode and a $1 \mathrm{k} \times 1 \mathrm{k}$ CCD camera (GATAN MS794). Acceleration voltage was set to $220 \mathrm{kV}$ and samples were prepared on 300 mesh $\mathrm{Cu}$ grids with Holey carbon film.

2.4. Powder X-Ray Diffraction. Powder X-ray diffraction patterns were obtained using an X'Pert PRO diffractometer (PANalytical, $40 \mathrm{kV}, 40 \mathrm{~mA}$ ) in theta/theta geometry equipped with a solid-state multichannel detector (PIXel). $\mathrm{Cu} \mathrm{K} \alpha$ radiation was used. Wide-angle diffraction scans were collected in reflection mode. Small-angle diffraction patterns were measured in transmission mode between $0.4^{\circ}$ and $6^{\circ} 2 \theta$ in steps of $0.013^{\circ} 2 \theta$ with a sampling time of $90 \mathrm{~s} / \mathrm{step}$.

2.5. Diffuse Reflectance UV-Vis Spectroscopy. Diffuse reflectance UV-Vis (DR-UV-Vis) spectroscopy was conducted on a two-beam spectrometer (V-670, Jasco) using a barium sulfate coated integration sphere (scan speed: $100 \mathrm{~nm} / \mathrm{min}$; slit width: $5.0 \mathrm{~nm}$ (UV-Vis) and $20 \mathrm{~nm}$ (NIR); and spectral region: $2000-220 \mathrm{~nm}$ ). SBA-15 was used as white standard for all samples.

2.6. Mössbauer Spectroscopy. Zero-field ${ }^{57} \mathrm{Fe}$ Mössbauer spectroscopic measurements were conducted on a transmission spectrometer with sinusoidal velocity sweep. Velocity calibration was done with an $\alpha$-Fe foil at ambient temperature. Measurements of samples $2.0 \mathrm{wt} \%$ Fe_Nitrate and $7.2 \mathrm{wt} \% \mathrm{Fe}_{-}$Nitrate were performed using a Janis closedcycle cryostat with the sample container entirely immersed in Helium exchange gas at 14 and $300 \mathrm{~K}$. Combined with measurements over a time period of about one to twelve days, the helium exchange gas ensured a gradient-free sample temperature. The sample temperature was recorded with a calibrated Si diode located close to the sample container made of Teflon or PEEK (polyether ether ketone), providing a temperature stability of better than $0.1 \mathrm{~K}$. Additional measurements of samples $9.3 \mathrm{wt} \% \mathrm{Fe} \_$Nitrate, $7.2 \mathrm{wt} \% \mathrm{Fe} \_$Nitrate, $2.0 \mathrm{wt} \%$ Fe_Nitrate, and $10.7 \mathrm{wt} \%$ Fe_Citrate were carried out on a spectrometer equipped with a Cryovac continuous flow cryostat with comparable specifications, geometry, and sample environment as described above. The nominal activity of the Mössbauer sources used was about $50 \mathrm{mCi}$ of ${ }^{57} \mathrm{Co}$ in a rhodium matrix. Spectra at $4 \mathrm{~K}$ were recorded every 30 minutes during overall measurement duration. Each Mössbauer spectrum shown here corresponds to the last 
spectrum in the respective series. Quantitative analysis of the recorded spectra was conducted on basis of the stochastic relaxation model developed by Blume and Tjon [15], in which the magnetic hyperfine field $B_{\mathrm{hf}}$ fluctuates randomly between two directions $\left(+B_{\mathrm{hf}}\right.$ and $\left.-B_{\mathrm{hf}}\right)$ along the symmetry axis of an axially symmetric electric field gradient tensor. Using this model is motivated by the observation of a significant line broadening, in particular in the spectra obtained for $7.2 \mathrm{wt} \%$ $\mathrm{Fe}_{-}$Nitrate at intermediate temperatures of ca. 60 and $100 \mathrm{~K}$, suggesting the presence of slow relaxation processes with relaxation times $\tau_{c}$ that are long or of the same order of magnitude as the Larmor precession time of the ${ }^{57}$ Fe nuclear magnetic moment (i.e., $10^{-6} \mathrm{~s}<\tau_{c}<10^{-8} \mathrm{~s}$ ). The quadrupole shift $\varepsilon$ is given by $e^{2} q Q / 4$, assuming that $e^{2} q Q \ll \mu B_{\mathrm{hf}}$ (constants $\mu, e, q$, and $Q$ were used in their usual meaning). The isomer shift $\delta$ is reported with respect to iron metal at ambient temperature and was not corrected in terms of the second-order Doppler shift.

2.7. Temperature-Programmed Reduction. Temperature-programmed reduction (TPR) was performed using a BELCATB (BEL Japan, Inc.). Samples were placed on silica wool in a silica glass tube reactor. Evolving water was trapped using a molecular sieve ( $4 \AA$ ). Gas mixture consisted of $5 \% \mathrm{H}_{2}$ in $95 \%$ Ar with a total gas flow of $40 \mathrm{ml} / \mathrm{min}$. Heating rates used were $5,10,15$, and $20 \mathrm{~K} / \mathrm{min}$ to $1223 \mathrm{~K}$. A constant initial sample weight was used and $\mathrm{H}_{2}$ consumption was continuously monitored by a thermal conductivity detector.

\section{Results and Discussion}

\subsection{Sample Characterization}

3.1.1. Nitrogen Physisorption Measurements. $\mathrm{Fe}_{x} \mathrm{O}_{y} / \mathrm{SBA}-15$ samples and support material SBA-15 exhibited type IV nitrogen adsorption/desorption isotherms indicating mesoporous materials (Figure 1). Adsorption and desorption branches were nearly parallel at the hysteresis loop, as expected for regularly shaped pores. Both SBA-15 and $\mathrm{Fe}_{x} \mathrm{O}_{y} / \mathrm{SBA}-15$ samples exhibited high specific surface areas with narrow pore size distributions. Independent of the used precursor, low loaded $\mathrm{Fe}_{x} \mathrm{O}_{y} / \mathrm{SBA}-15$ samples showed significantly higher specific surface areas than higher loaded samples. Compared to SBA-15, all $\mathrm{Fe}_{x} \mathrm{O}_{y} / \mathrm{SBA}-15$ samples showed a decrease in specific surface area. Whereas SBA15 possessed a BET-surface between 743.4 and $779.4 \mathrm{~m}^{2} / \mathrm{g}$, those of the $\mathrm{Fe}_{x} \mathrm{O}_{y} / \mathrm{SBA}-15$ samples were determined to be between 605.9 and $725.2 \mathrm{~m}^{2} / \mathrm{g}$. Pore size distribution was calculated by the $\mathrm{BJH}$ method and revealed a decrease in pore radius from $4.6 \mathrm{~nm}$ of SBA-15 to $4.0 \mathrm{~nm}$ of $\mathrm{Fe}_{x} \mathrm{O}_{y} / \mathrm{SBA}$ 15 samples. This decrease in specific surface area as well as the decrease in pore radius with increasing iron loading indicated the presence of iron species in the mesopores of SBA-15. Moreover, transmission electron microscopy (TEM) measurements of the $\mathrm{Fe}_{x} \mathrm{O}_{y} / \mathrm{SBA}-15$ samples also indicated that iron species were located in the pore system of SBA-15 with no iron species detected on the external surface of SBA15. TEM micrograph of the highest loaded nitrate sample,

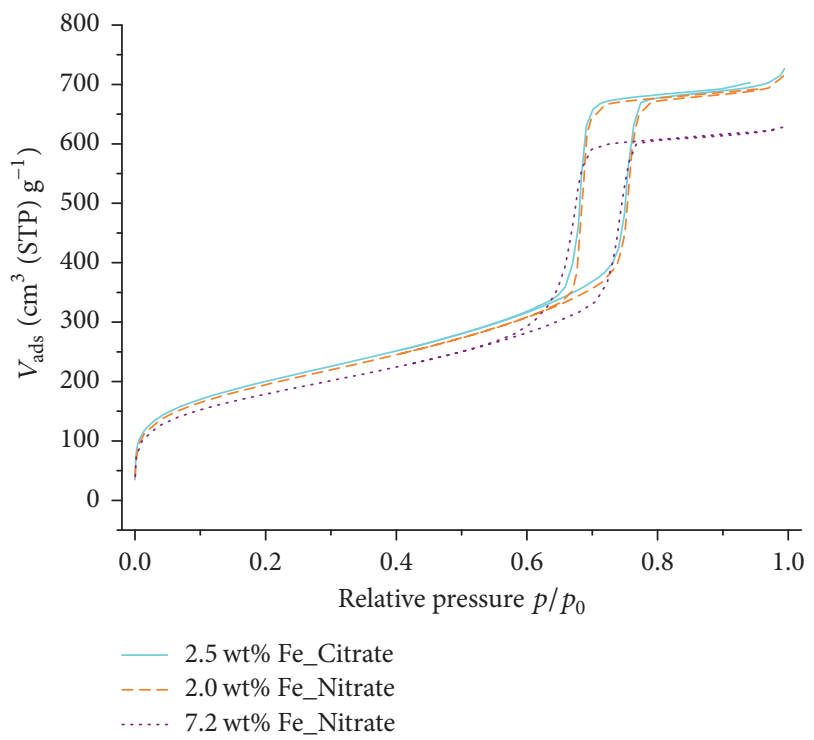

FIGURE 1: Nitrogen adsorption/desorption isotherms of the samples $2.5 \mathrm{wt} \% \mathrm{Fe} \_$Citrate (straight lines), $2.0 \mathrm{wt} \% \mathrm{Fe} \_$Nitrate (dashed lines), and $7.2 \mathrm{wt} \% \mathrm{Fe} \_$Nitrate (dotted lines).

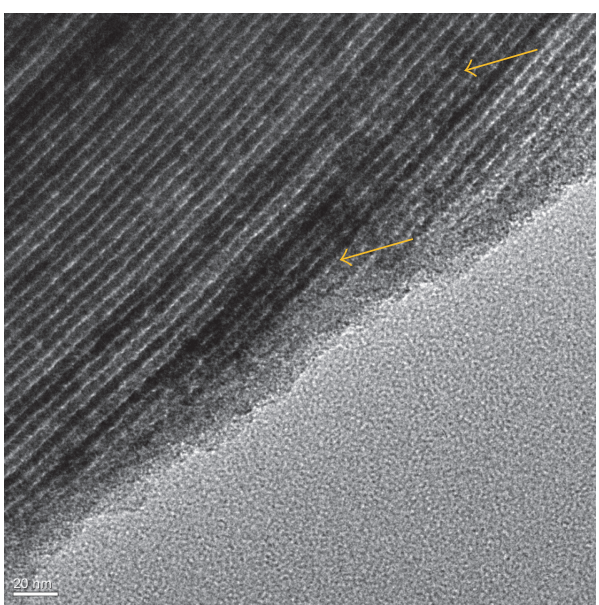

Figure 2: TEM micrograph of sample $9.3 \mathrm{wt} \%$ Fe_Nitrate. Dark contrast (arrows) indicates the iron species.

9.3 wt $\%$ Fe_Nitrate, is depicted in Figure 2. The dark contrast (arrows in Figure 2) indicated the presence of iron species in the pore channels of SBA- 15 .

In addition to BET method and $\mathrm{BJH}$ method, the modified FHH method was used to analyze the nitrogen physisorption data. Herein, the fractal dimension $D_{f}$ was determined as a measure of the roughness of the surface $[16,17]$. For $\mathrm{Fe}_{x} \mathrm{O}_{y} / \mathrm{SBA}-15$ samples, as well as SBA-15, the fractal dimension was between 2 and 3 . This indicated a rough surface. In order to elucidate the effect of supported iron species on surface roughness of the support material, $\Delta D_{f}$ values were calculated as difference from $D_{f}$ values of SBA-15 and those of the corresponding $\mathrm{Fe}_{x} \mathrm{O}_{y} / \mathrm{SBA}-15$ samples. In contrast to the nitrate samples, citrate samples possessed significantly higher values of $\Delta D_{f}$ (Tables 1 and 2 ). Therefore, compared to those of the nitrate samples, the 
TABLE 1: Characteristics of $\mathrm{Fe}_{x} \mathrm{O}_{y} / \mathrm{SBA}-15$ samples: specific surface area, $a_{\mathrm{BET}}$ (BET method), pore volume, $V_{\text {Pore, }}$, and average pore radius, $r_{\text {Pore }}\left(\mathrm{BJH}\right.$ method), unit cell parameter, $a$ (hexagonal pore system), and difference in fractal dimension, $\Delta D_{f}$ (difference before and after deposition of iron species on SBA-15 (Table 2), modified FHH method).

\begin{tabular}{|c|c|c|c|c|c|}
\hline Sample & $a_{s, \mathrm{BET}} / \mathrm{m}^{2} / \mathrm{g}$ & $V_{\text {pore }} / \mathrm{cm}^{3} / \mathrm{g}$ & $r_{\text {pore }} / \mathrm{nm}$ & $a / \mathrm{nm}$ & $\Delta D_{f}$ \\
\hline $2.5 \mathrm{wt} \% \mathrm{Fe} \_$Citrate & $725.2 \pm 0.7$ & $1.112 \pm 0.001$ & $4.030 \pm 0.004$ & $11.15 \pm 0.02$ & $0.12 \pm 0.02$ \\
\hline $6.3 \mathrm{wt} \% \mathrm{Fe} \_$Citrate & $650.9 \pm 0.7$ & $0.968 \pm 0.001$ & $4.030 \pm 0.004$ & $11.02 \pm 0.02$ & $0.21 \pm 0.05$ \\
\hline $10.7 \mathrm{wt} \% \mathrm{Fe} \_$Citrate & $605.7 \pm 0.6$ & $0.898 \pm 0.001$ & $4.030 \pm 0.004$ & $10.94 \pm 0.02$ & $0.15 \pm 0.01$ \\
\hline $2.0 \mathrm{wt} \% \mathrm{Fe} \_$Nitrate & $703.0 \pm 0.7$ & $1.096 \pm 0.001$ & $4.030 \pm 0.004$ & $11.16 \pm 0.01$ & $0.06 \pm 0.01$ \\
\hline $7.2 \mathrm{wt} \% \mathrm{Fe} \_$Nitrate & $647.8 \pm 0.6$ & $0.971 \pm 0.001$ & $4.03 \pm 0.004$ & $11.11 \pm 0.02$ & $0.07 \pm 0.01$ \\
\hline 9.3 wt $\%$ Fe_Nitrate & $633.1 \pm 0.6$ & $0.939 \pm 0.001$ & $4.03 \pm 0.004$ & $11.10 \pm 0.01$ & $-0.06 \pm 0.02$ \\
\hline
\end{tabular}

surface of the citrate samples appeared to be smoother. A possible explanation for the differences in surface roughness of the support material might be the differently pronounced chelating effect of the two precursors. The citrate precursor showed a more pronounced chelating effect and, therefore, stronger bonds between citrate ligands and $\mathrm{Fe}(\mathrm{III})$ central atoms. Due to the stronger bonds between citrate ligands and $\mathrm{Fe}(\mathrm{III})$ atoms, polydentate citrate ligands encapsulated the Fe(III) ions, thereby preventing agglomeration of iron species during calcination. Thus, after calcination and removal of the citrate ligands, the resulting $\mathrm{Fe}(\mathrm{III})$ species were more isolated and dispersed on the support material. Conversely, nitrate ligands showed minor interactions with the $\mathrm{Fe}(\mathrm{III})$ ions due to the less pronounced chelating effect. Therefore, nitrate removal during calcination was facilitated and the resulting $\mathrm{Fe}(\mathrm{III})$ species readily aggregated and formed less dispersed iron oxide species on the support material $[16,17]$.

3.1.2. X-Ray Diffraction. Figure 3 depicts the small-angle XRD patterns of the $\mathrm{Fe}_{x} \mathrm{O}_{y} / \mathrm{SBA}-15$ samples and the mechanical mixture $\mathrm{Fe}_{2} \mathrm{O}_{3} / \mathrm{SBA}-15$. Diffraction peaks (101), (11l), and (20l) correspond to the two-dimensional hexagonal symmetry of SBA-15. The diffraction peaks were visible for all samples and the mechanical mixture $\mathrm{Fe}_{2} \mathrm{O}_{3} / \mathrm{SBA}-15$. Wideangle $\mathrm{X}$-ray diffraction patterns of the $\mathrm{Fe}_{x} \mathrm{O}_{y} / \mathrm{SBA}-15$ samples showed no long-range ordered phases indicative of small and isolated iron species (Figure 4). Conversely, XRD patterns of the mechanical mixture of SBA-15 and $\mathrm{Fe}_{2} \mathrm{O}_{3}$ showed diffraction peaks of crystalline $\mathrm{Fe}_{2} \mathrm{O}_{3}$.

3.1.3. Diffuse Reflectance UV-Vis Spectroscopy. DR-UV-Vis spectra of the $\mathrm{Fe}_{x} \mathrm{O}_{y} / \mathrm{SBA}-15$ samples are depicted in Figure 5(a). Independent of the utilized precursor, a red-shift and broadening of the absorption bands with increasing iron loading can be seen (Figure 5(a)). The red-shift of the absorption and, thus, a decreasing edge energy with increasing iron loading can be correlated with an aggregation of $\mathrm{Fe}(\mathrm{III})$ species [18, 19]. All $\mathrm{Fe}_{x} \mathrm{O}_{y} / \mathrm{SBA}-15$ samples possessed edge energy values higher than $2.1 \mathrm{eV}$ (edge energy in the DR-UVVis spectrum of crystalline $\mathrm{Fe}_{2} \mathrm{O}_{3}$ ). Hence, the size of the supported iron species was smaller than that of crystalline $\mathrm{Fe}_{2} \mathrm{O}_{3}$ in all samples. Both citrate samples and nitrate samples exhibited a decrease in edge energy with increased iron loading (Figure 5(b)). However, the citrate samples showed higher

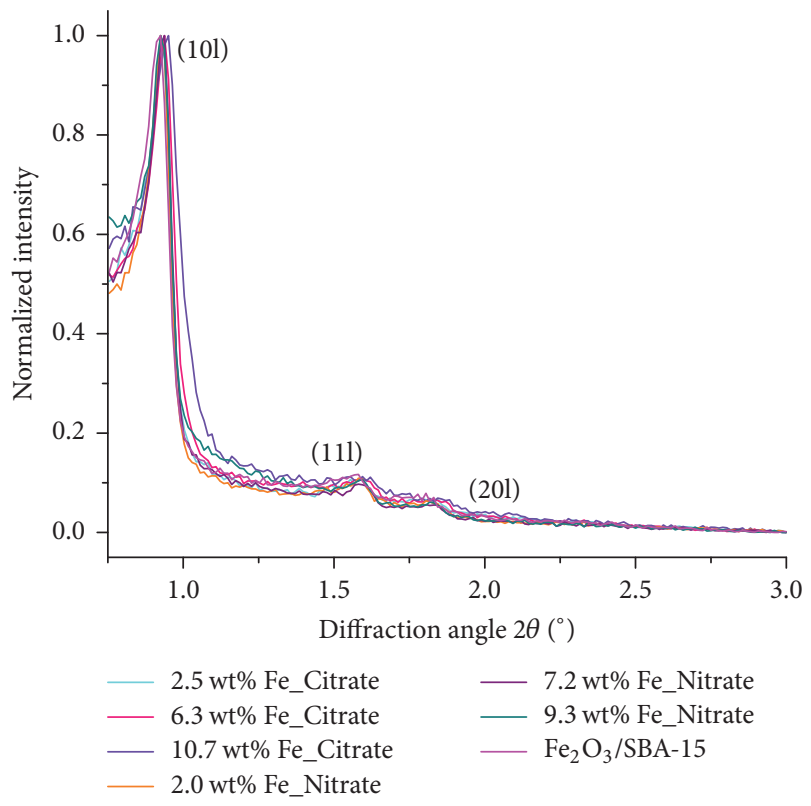

FIgURE 3: Small-angle X-ray diffraction patterns of all $\mathrm{Fe}_{x} \mathrm{O}_{y} / \mathrm{SBA}$ 15 samples and the mechanical mixture $\mathrm{Fe}_{2} \mathrm{O}_{3} /$ SBA- 15 .

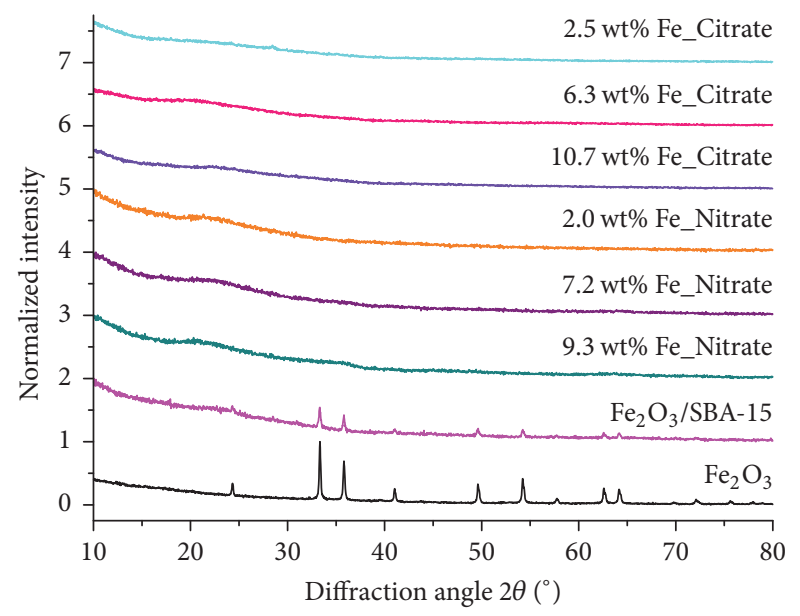

Figure 4: Wide-angle X-ray diffraction patterns of all $\mathrm{Fe}_{x} \mathrm{O}_{y} / \mathrm{SBA}$ 15 samples, a reference (mechanically mixed SBA-15 and crystalline $\mathrm{Fe}_{2} \mathrm{O}_{3}$ ), and crystalline $\mathrm{Fe}_{2} \mathrm{O}_{3}$. 
TABLE 2: Fractal dimension, $D_{f}$, of all $\mathrm{Fe}_{x} \mathrm{O}_{y} / \mathrm{SBA}-15$ samples and corresponding SBA-15 (modified FHH method) and difference in fractal dimension, $\Delta D_{f}$, between $\mathrm{SBA}-15$ and corresponding $\mathrm{Fe}_{x} \mathrm{O}_{y} / \mathrm{SBA}-15$ samples.

\begin{tabular}{lccc}
\hline Sample & $D_{f}$ & $D_{f}($ SBA-15) & $\Delta D_{f}$ \\
\hline 2.5 wt\% Fe_Citrate & $2.520 \pm 0.009$ & $2.637 \pm 0.006$ & $0.12 \pm 0.02$ \\
6.3 wt\% Fe_Citrate & $2.350 \pm 0.042$ & $2.563 \pm 0.011$ & $0.21 \pm 0.05$ \\
10.7 wt\% Fe_Citrate & $2.345 \pm 0.039$ & $2.497 \pm 0.014$ & $0.15 \pm 0.01$ \\
2.0 wt\% Fe_Nitrate & $2.549 \pm 0.005$ & $2.604 \pm 0.004$ & $0.06 \pm 0.01$ \\
7.2 wt\% Fe_Nitrate & $2.550 \pm 0.004$ & $2.617 \pm 0.005$ & $0.07 \pm 0.01$ \\
9.3 wt\% Fe_Nitrate & $2.613 \pm 0.009$ & $2.557 \pm 0.007$ & $-0.06 \pm 0.02$ \\
\hline
\end{tabular}

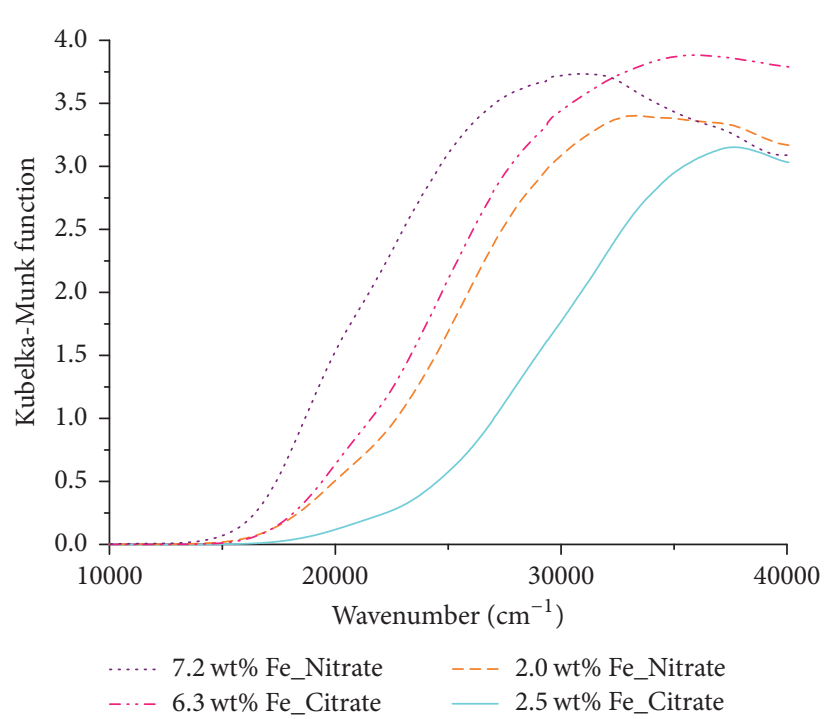

(a)

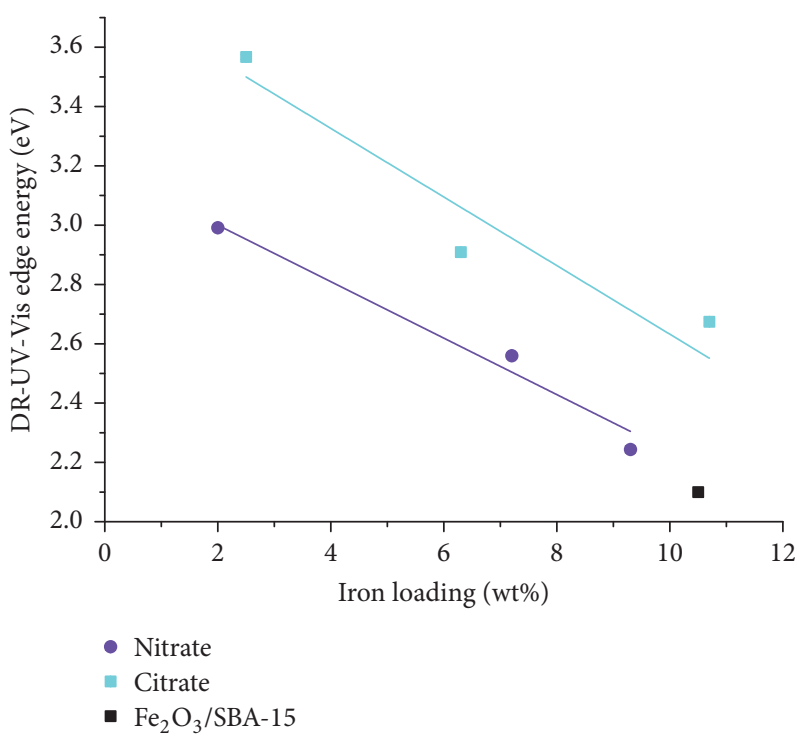

(b)

Figure 5: (a) DR-UV-Vis spectra of $2.5 \mathrm{wt} \%$ Fe_Citrate (straight line), $2.0 \mathrm{wt} \%$ Fe_Nitrate (dashed line), 6.3 wt\% Fe_Citrate (dashed doubledotted line), and $7.2 \mathrm{wt} \% \mathrm{Fe} \_$Nitrate (dotted line). (b) Edge energy as function of iron loading for nitrate samples (circles), citrate samples (squares), and mechanical mixture (square).

edge energy values than the corresponding nitrate samples. Therefore, iron species obtained by citrate precursor were smaller compared to those obtained by nitrate precursor.

3.1.4. Mössbauer Spectroscopy. Mössbauer spectra of $9.3 \mathrm{wt} \%$ Fe_Nitrate and 10.7 wt\% Fe_Citrate recorded above $200 \mathrm{~K}$ showed a broadened and asymmetric doublet independent of the used precursor. Therefore, this doublet was analyzed using two nonequivalent Fe sites. The determined values for the isomer shift $\delta$ and the quadrupole shift $\varepsilon$ are consistent with those reported for superparamagnetic particles of $\mathrm{Fe}_{2} \mathrm{O}_{3}$ $[20,21]$. At low temperatures, that is, at $14 \mathrm{~K}$ for $9.3 \mathrm{wt} \%$ Fe_Nitrate and at $4 \mathrm{~K}$ for $10.7 \mathrm{wt} \%$ Fe_Citrate (Figure 6), the doublet almost disappeared and a magnetically split hyperfine pattern was detected. This observation indicated the presence of small superparamagnetic iron oxidic species. The related Mössbauer parameters (Table 3) are furthermore consistent with those reported for (magnetically blocked) superparamagnetic particles with a local geometry similar to $\mathrm{Fe}_{2} \mathrm{O}_{3}$ supported on SBA-15 [20]. Therefore, a blocking temperature lower than $200 \mathrm{~K}$ implied an upper limit for the Fe species diameter of $<10 \mathrm{~nm}$ [22] for $9.3 \mathrm{wt} \%$ Fe_Nitrate.
Conversely, the observation of an almost complete blocking at lower temperatures for $10.7 \mathrm{wt} \% \mathrm{Fe}$-Citrate compared to 9.3 wt $\%$ Fe_Nitrate suggested a significantly smaller species size obtained from citrate precursor. Furthermore, refinement of the Mössbauer spectra of $9.3 \mathrm{wt} \%$ Fe_Nitrate and $7.2 \mathrm{wt} \% \mathrm{Fe} \_$Nitrate at $14 \mathrm{~K}$ and of $10.7 \mathrm{wt} \%$ Fe_Citrate at $14 \mathrm{~K}$ and $4 \mathrm{~K}$ required an additional component (Table 3), indicating a bimodal particle size distribution.

The Mössbauer spectra of the lower loaded nitrate samples, $7.2 \mathrm{wt} \%$ Fe_Nitrate and $2.0 \mathrm{wt} \%$ Fe_Nitrate, also exhibited a broadened and asymmetric doublet at $300 \mathrm{~K}$ with similar values for isomer shift and quadrupole splitting as determined for $9.3 \mathrm{wt} \%$ Fe_Nitrate. While this doublet almost completely transformed into a magnetically split sextet for sample $9.3 \mathrm{wt} \% \mathrm{Fe} \_$Nitrate at $14 \mathrm{~K}$ (vide supra), this transformation remained incomplete in the Mössbauer spectra of $7.2 \mathrm{wt} \%$ Fe_Nitrate and $2.0 \mathrm{wt} \%$ Fe_Nitrate at $14 \mathrm{~K}$ (Figure 7). The determined site population ratio of the doublet relative to the magnetically split sextet signal increased systematically with decreasing iron loading from about 2:98 for $9.3 \mathrm{wt} \%$ Fe_Nitrate to $45: 55$ for 2.0 wt\% Fe_Nitrate (Table 3). Furthermore, a similar trend was observed for the determined values 


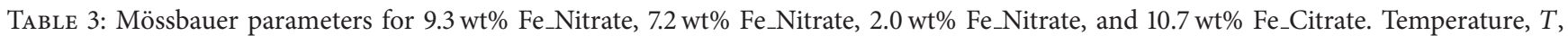
isomer shift, $\delta$ (referred to $\alpha$-Fe at $298 \mathrm{~K}$ and not corrected for 2 nd-order Doppler shift), quadrupole shift, $\varepsilon$, line widths, $\Gamma_{\mathrm{HWHM}}$, hyperfine magnetic field, $B_{\mathrm{hf}}$, fluctuation rate, $v_{c}$, and area. * indicates values held fixed in simulation. [a] indicates that relaxation rate reached the dynamic limit.

\begin{tabular}{|c|c|c|c|c|c|c|c|}
\hline Sample & $T / K$ & $\delta / \mathrm{mm} / \mathrm{s}$ & $\varepsilon / \mathrm{mm} / \mathrm{s}$ & $\Gamma_{\mathrm{HWHM}} / \mathrm{mm} / \mathrm{s}$ & $B_{\mathrm{hf}} / \mathrm{T}$ & $v_{C} / \mathrm{mm} / \mathrm{s}$ & Area/\% \\
\hline \multirow{5}{*}{9.3 wt $\%$ Fe_Nitrate } & \multirow{2}{*}{300} & $0.320(9)$ & $0.173(42)$ & $0.29(11)$ & $48.3^{*}$ & {$[a]$} & 48 \\
\hline & & $0.327(8)$ & $0.536(37)$ & $0.277(45)$ & $48.3^{*}$ & {$[a]$} & 52 \\
\hline & \multirow{3}{*}{14} & $0.401(21)$ & $-0.012(20)$ & $0.28^{*}$ & $46.5(2.7)$ & 0.13 & 45 \\
\hline & & $0.465(11)$ & $-0.018(11)$ & $0.28^{*}$ & $50.0(1.2)$ & 0.02 & 52 \\
\hline & & $0.401^{*}$ & $0.43^{*}$ & $0.37^{*}$ & $48.3^{*}$ & $310^{*}$ & 3 \\
\hline \multirow{5}{*}{7.2 wt $\%$ Fe_Nitrate } & \multirow{2}{*}{300} & $0.330(5)$ & $0.299(15)$ & $0.190(16)$ & $48.3^{*}$ & {$[a]$} & 52 \\
\hline & & $0.307(7)$ & $0.508(27)$ & $0.233(17)$ & $48.3^{*}$ & {$[a]$} & 48 \\
\hline & \multirow{3}{*}{14} & $0.394(35)$ & $-0.014(43)$ & $0.23^{*}$ & $45.4(5)$ & 0.3 & 49 \\
\hline & & $0.462(19)$ & $-0.034(19)$ & $0.23^{*}$ & $49.7(2)$ & 0.1 & 39 \\
\hline & & $0.431(72)$ & $0.518(59)$ & $0.45^{*}$ & $48.3^{*}$ & {$[a]$} & 12 \\
\hline \multirow{4}{*}{2.0 wt $\%$ Fe_Nitrate } & \multirow{2}{*}{300} & $0.336(15)$ & $0.346(78)$ & $0.273(60)$ & $48.3^{*}$ & {$[a]$} & 60 \\
\hline & & $0.312(21)$ & $0.583(95)$ & $0.265(71)$ & $48.3^{*}$ & {$[a]$} & 40 \\
\hline & \multirow{2}{*}{14} & $0.421^{*}$ & $0.08(12)$ & $0.24(76)$ & $43.8(1.5)$ & 0.7 & 55 \\
\hline & & $0.423(48)$ & $0.500(60)$ & $0.437(80)$ & $48.3^{*}$ & 520 & 45 \\
\hline \multirow{10}{*}{10.7 wt $\%$ Fe_Citrate } & \multirow{2}{*}{300} & $0.294(12)$ & $0.206(39)$ & $0.34(12)$ & $48.3^{*}$ & {$[a]$} & 45 \\
\hline & & $0.316(12)$ & $0.672(50)$ & $0.376(49)$ & $48.3^{*}$ & {$[a]$} & 55 \\
\hline & \multirow{4}{*}{14} & $0.451^{*}$ & $-0.008(64)$ & $0.20^{*}$ & $43.5^{*}$ & 5.6 & 34 \\
\hline & & $0.451(10)$ & $-0.005(97)$ & $0.20^{*}$ & $43.5(7)$ & 0.5 & 31 \\
\hline & & $0.438(15)$ & $0.466(22)$ & $0.23^{*}$ & $48.3^{*}$ & {$[a]$} & 25 \\
\hline & & $0.416(38)$ & $0.814(50)$ & $0.23^{*}$ & $48.3^{*}$ & {$[a]$} & 10 \\
\hline & \multirow{4}{*}{4} & $0.497(62)$ & $0.018(62)$ & $0.20^{*}$ & $48.9(5)$ & 0.05 & 14 \\
\hline & & $0.424(47)$ & $-0.026(45)$ & $0.20^{*}$ & $45.0(6)$ & 0.45 & 81 \\
\hline & & $0.438^{*}$ & $0.47^{*}$ & $0.23^{*}$ & $48.3^{*}$ & {$[a]$} & 1 \\
\hline & & $0.416^{*}$ & $0.81^{*}$ & $0.23^{*}$ & $48.3^{*}$ & {$[a]$} & 4 \\
\hline
\end{tabular}

of the local magnetic hyperfine field (i.e., decreasing $B_{\mathrm{hf}}$ with decreasing Fe loading). Assuming that all iron in the nitrate samples consisted of iron oxide, both results independently suggested a correlation of increasing average iron species size and increasing iron loading within the nitrate samples.

3.1.5. Temperature-Programmed Reduction. Figures 8 and 9 depict TPR traces of $\mathrm{Fe}_{x} \mathrm{O}_{y} / \mathrm{SBA}-15$ samples measured during reduction with $\mathrm{H}_{2}$ at a heating rate of $10 \mathrm{~K} / \mathrm{min}$. Significant differences in reduction profiles are discernible. Lowest loaded citrate and nitrate samples possessed one single reduction peak. Conversely, higher loaded citrate samples showed a two-step reduction (not considering a very small second TPR peak for sample $10.7 \mathrm{wt} \% \mathrm{Fe}$ _Citrate), while higher loaded nitrate samples showed a three-step reduction. The first reduction step can be assigned to the reduction of $\mathrm{Fe}(\mathrm{III})$ oxidic species to $\mathrm{Fe}(\mathrm{II})$ oxidic species. The small iron species of the lowest loaded citrate and nitrate sample interacted strongly with the surface of SBA- 15 , preventing further reduction in the applied temperature range. Hence, these samples showed only one single reduction peak in the TPR profile. Conversely, the larger iron species in the higher loaded citrate and nitrate samples exhibited further reduction of the $\mathrm{Fe}$ (II) species and, hence, a two-step or even three-step reduction mechanism. Thus, increasing iron loading resulted in weaker interactions between iron species and support material.

For both, nitrate and citrate samples, an increasing temperature of the first TPR maxima correlated with an increasing iron loading. Furthermore, nitrate samples showed a shift of the TPR maxima to lower temperatures compared to the citrate samples. This shift of the TPR maxima indicated better reducibility of the nitrate samples. The mechanical mixture $\mathrm{Fe}_{2} \mathrm{O}_{3} /$ SBA-15 exhibited two TPR maxima with a shoulder at the second TPR peak, indicating a three-step reduction (Figure 10). TPR traces of the mechanical mixture differed significantly from those of the $\mathrm{Fe}_{x} \mathrm{O}_{y} / \mathrm{SBA}-15$ samples. Moreover, neither the $\mathrm{Fe}_{x} \mathrm{O}_{y} / \mathrm{SBA}-15$ samples nor the mechanical mixture showed a TPR profile characteristic for crystalline $\mathrm{Fe}_{2} \mathrm{O}_{3}$ (Figure 10). Differences in the TPR profiles of the mechanical mixture and crystalline $\mathrm{Fe}_{2} \mathrm{O}_{3}$ resulted from differences in both particle sizes and dispersion of $\mathrm{Fe}_{2} \mathrm{O}_{3}$ crystallites [23]. Dispersion of smaller $\mathrm{Fe}_{2} \mathrm{O}_{3}$ crystallites on SBA-15 in the mechanical mixture compared to pure $\mathrm{Fe}_{2} \mathrm{O}_{3}$ induced a decreased first TPR peak and a shift of the second TPR peak to lower temperature. Significantly smaller $\mathrm{Fe}_{2} \mathrm{O}_{3}$ crystallites of the mechanical mixture correlated with a significantly decreased first reduction peak [23]. 


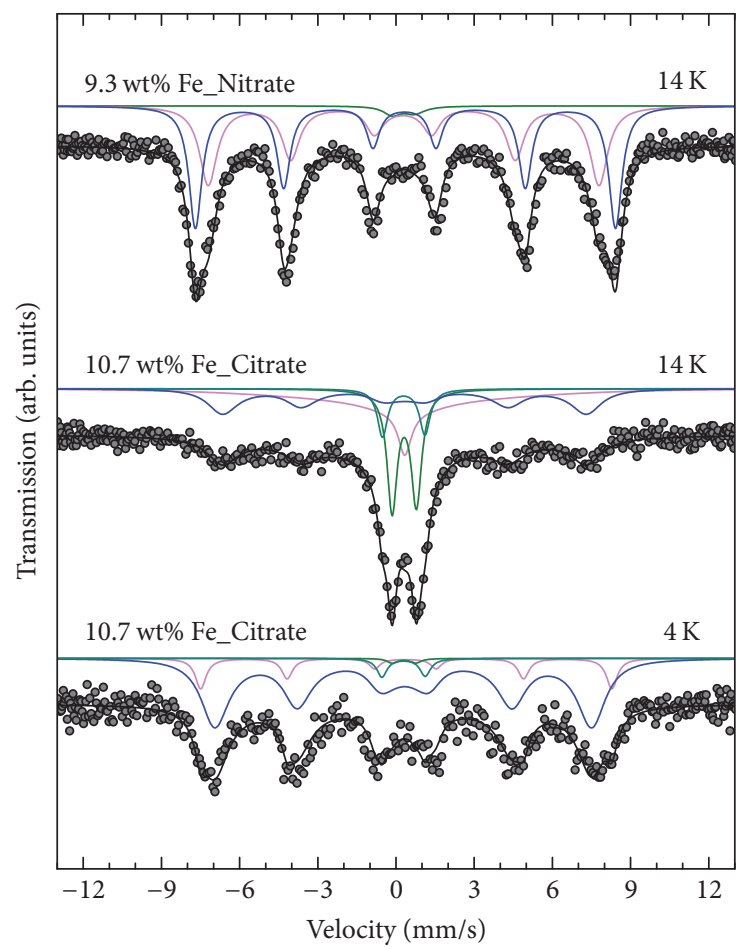

Figure 6: Mössbauer spectra of $9.3 \mathrm{wt} \%$ Fe_Nitrate (top) and $10.7 \mathrm{wt} \% \mathrm{Fe}$-Citrate (middle and bottom) at 14 and $4 \mathrm{~K}$. Dots: experimental data; lines: fit curves based on stochastic Blume-Tjon relaxation model.

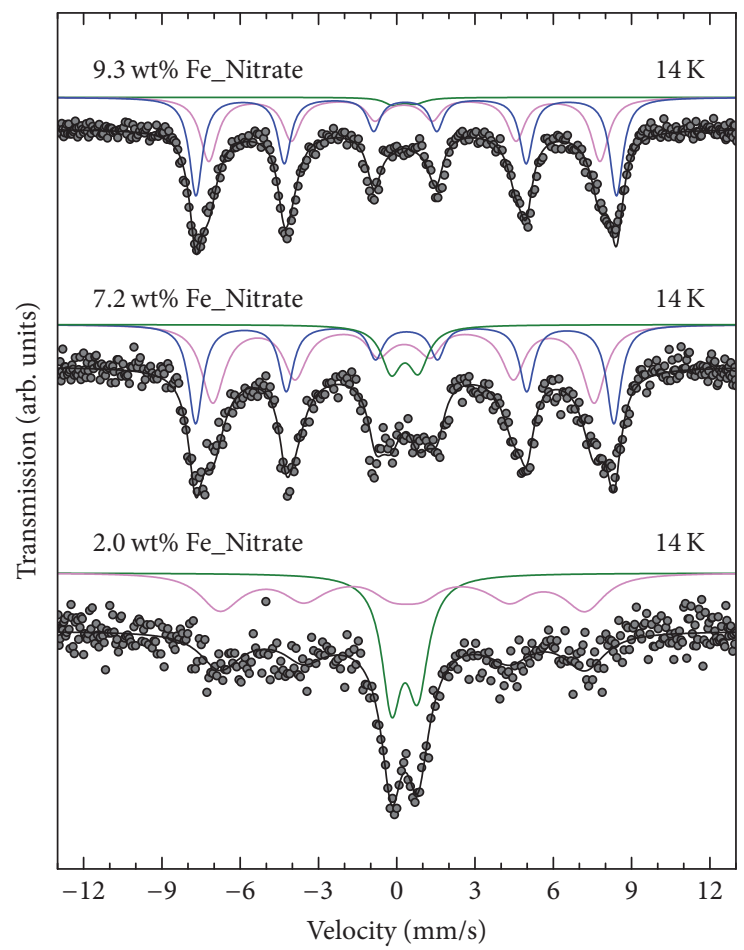

Figure 7: Mössbauer spectra of $9.3 \mathrm{wt} \%$ Fe_Nitrate (top), $7.2 \mathrm{wt} \%$ Fe_Nitrate (middle), and $2.0 \mathrm{wt} \%$ Fe_Nitrate (bottom) at $14 \mathrm{~K}$. Dots: experimental data; lines: fit curves based on stochastic Blume-Tjon relaxation model.

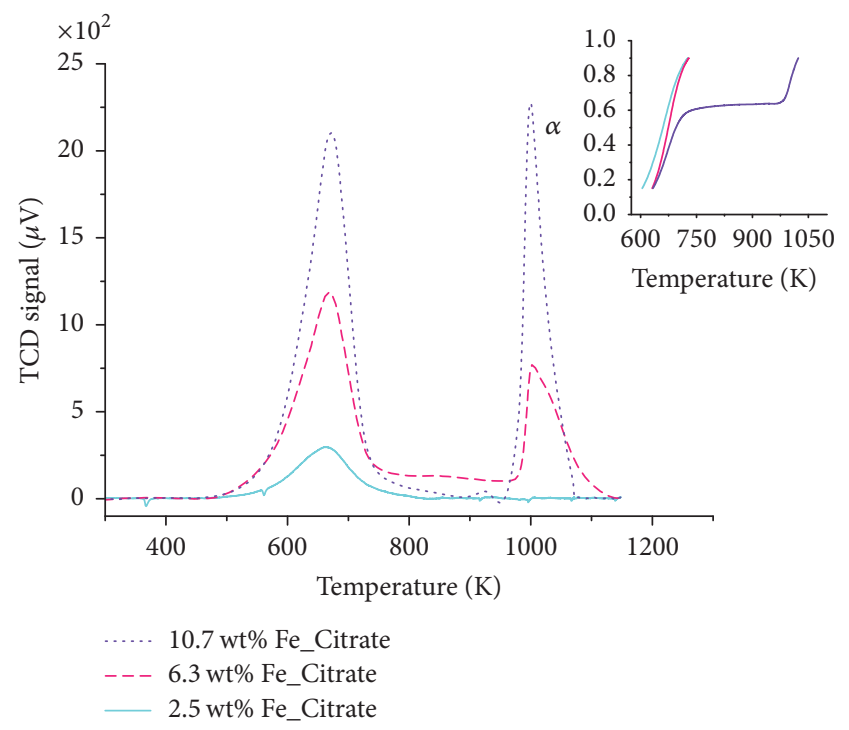

FIGURE 8: TPR traces of $2.5 \mathrm{wt} \%$ Fe_Citrate (straight line), $6.3 \mathrm{wt} \%$ Fe_Citrate (dashed line), and $10.7 \mathrm{wt} \% \mathrm{Fe}$-Citrate (dotted line) measured in $5 \% \mathrm{H}_{2}$ in $95 \%$ argon at $10 \mathrm{~K} / \mathrm{min}$. Inset depicts reduction degree traces with increasing iron loading from left to right.

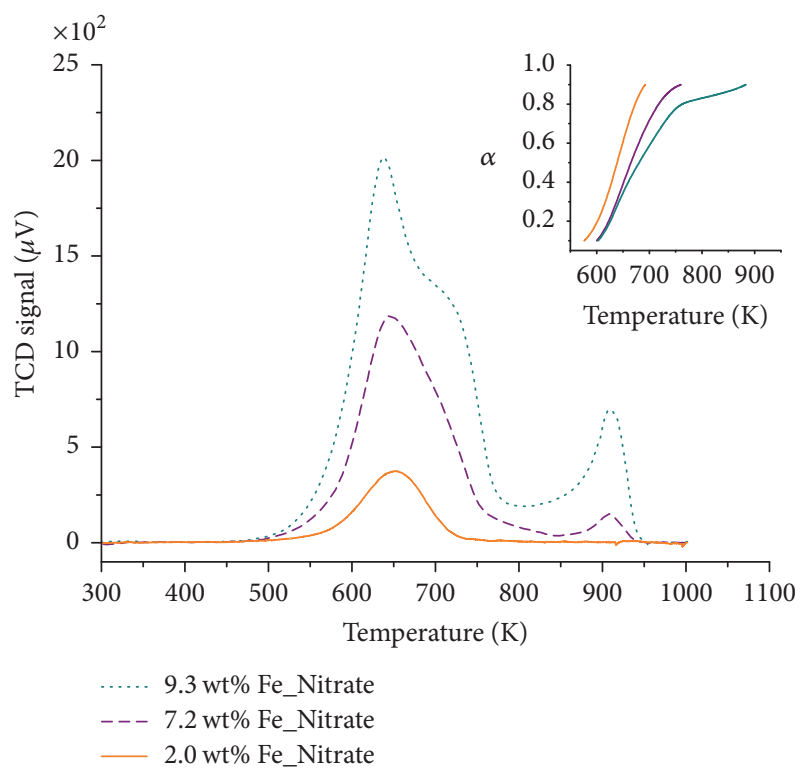

FIGURE 9: TPR traces of $2.0 \mathrm{wt} \% \mathrm{Fe} \_$Nitrate (straight line), $7.2 \mathrm{wt} \%$ Fe_Nitrate (dashed line), and $9.3 \mathrm{wt} \% \mathrm{Fe} \_N i t r a t e$ (dotted line) measured in $5 \% \mathrm{H}_{2}$ in $95 \%$ argon at $10 \mathrm{~K} / \mathrm{min}$. Inset depicts reduction degree traces with increasing iron loading from left to right.

3.2. Reduction Kinetics under Nonisothermal Conditions. In the following, a more detailed solid-state kinetic analysis of the reduction traces is presented. Besides TPR traces of all nitrate samples, those of the mechanical mixture and the lowest loaded citrate sample were analyzed. After transforming TPR traces to reduction degree $\alpha$ traces, model-independent and model-dependent solid-state kinetic analysis methods were applied. 


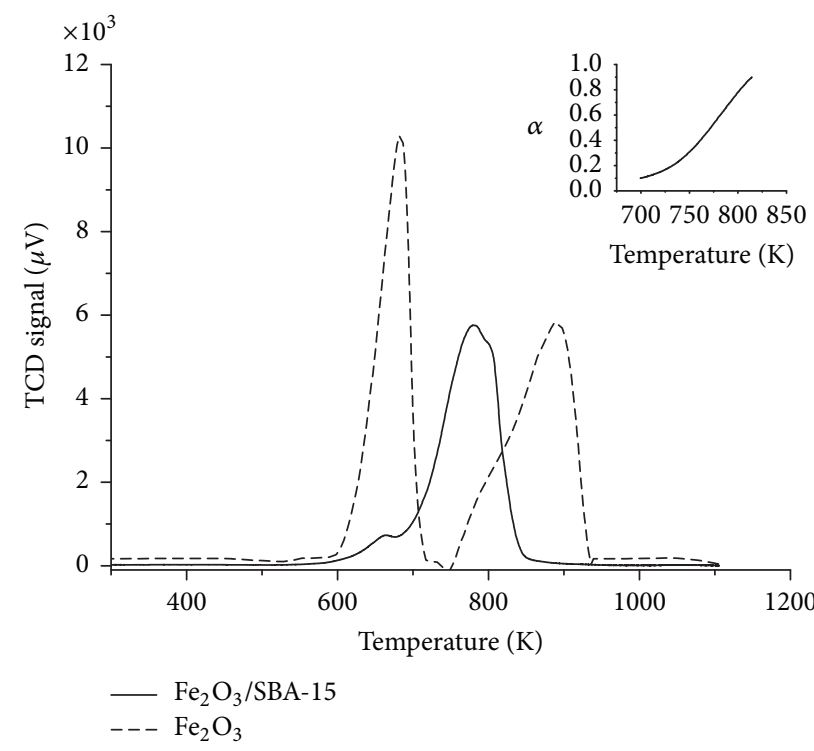

FIgURE 10: TPR traces of mechanical mixture $\mathrm{Fe}_{2} \mathrm{O}_{3} / \mathrm{SBA}-15$ (straight line) and crystalline $\mathrm{Fe}_{2} \mathrm{O}_{3}$ (dashed line) measured in 5\% $\mathrm{H}_{2}$ in $95 \%$ argon at $10 \mathrm{~K} / \mathrm{min}$. Inset depicts reduction degree trace.

All $\mathrm{Fe}_{x} \mathrm{O}_{y} / \mathrm{SBA}-15$ samples showed symmetrically shaped TPR profiles. This indicates no rate limitation by removal of the small amount of $\mathrm{H}_{2} \mathrm{O}$ formed by reduction of the low concentration of iron species on SBA-15. Additionally, mass transport limited processes exhibit characteristic apparent activation energies of less than $10 \mathrm{~kJ} / \mathrm{mol}$ [24]. Apparent activation energies for all $\mathrm{Fe}_{x} \mathrm{O}_{y} / \mathrm{SBA}-15$ samples were significantly higher than $10 \mathrm{~kJ} / \mathrm{mol}$. Therefore, mass transport limitation of reactant gas $\mathrm{H}_{2}$ was considered to be not ratelimiting in the reduction of $\mathrm{Fe}_{x} \mathrm{O}_{y} / \mathrm{SBA}-15$.

3.2.1. Kissinger Method. Apparent activation energy $E_{a}$ of the rate-determining step during reduction was determined by applying the Kissinger method. Therefore, $\ln \left[\beta / T_{m}{ }^{2}\right]$ was depicted as function of $1 / T_{m}[11,25]$. Here, $T_{m}$ corresponded to the first maximum of the TPR traces (Figures 8-10). From the slope of the resulting straight line, the apparent activation energy for the reduction of $\mathrm{Fe}_{x} \mathrm{O}_{y} / \mathrm{SBA}-15$ was calculated (Figure 11). The lowest loaded citrate sample possessed the lowest apparent activation energy of $39 \pm 8 \mathrm{~kJ} / \mathrm{mol}$. The highest apparent activation energy of $88 \pm 8 \mathrm{~kJ} / \mathrm{mol}$ was calculated for sample $2.0 \mathrm{wt} \% \mathrm{Fe}$ Nitrate (Table 4). Increasing the iron loading of the nitrate samples resulted in a decreasing apparent activation energy of the rate-determining step during reduction. Moreover, results of the Kissinger method also correlated with the species size resulting from DR-UVVis and Mössbauer spectroscopy. Hence, increasing size of the iron species of the nitrate samples was accompanied by better reducibility and a decreasing apparent activation energy of reduction. The apparent activation energy of the mechanical mixture was calculated to be $59 \pm 7 \mathrm{~kJ} / \mathrm{mol}$. This lower apparent activation energy compared to the nitrate samples was consistent with a further increased species size.
TABLE 4: Apparent activation energy of the rate-determining step in reduction of iron-containing samples in $5 \% \mathrm{H}_{2}$ as determined by Kissinger method.

\begin{tabular}{lc}
\hline Sample & $E_{a} / \mathrm{kJ} / \mathrm{mol}$ \\
\hline $2.5 \mathrm{wt} \% \mathrm{Fe} \_$Citrate & $39 \pm 8$ \\
$2.0 \mathrm{wt} \% \mathrm{Fe} \_N i t r a t e$ & $88 \pm 8$ \\
$7.2 \mathrm{wt} \% \mathrm{Fe} \_N i t r a t e$ & $84 \pm 1$ \\
$9.3 \mathrm{wt} \% \mathrm{Fe} \_N i t r a t e$ & $62 \pm 8$ \\
$\mathrm{Fe}_{2} \mathrm{O}_{3} / \mathrm{SBA}-15$ & $59 \pm 7$ \\
\hline
\end{tabular}

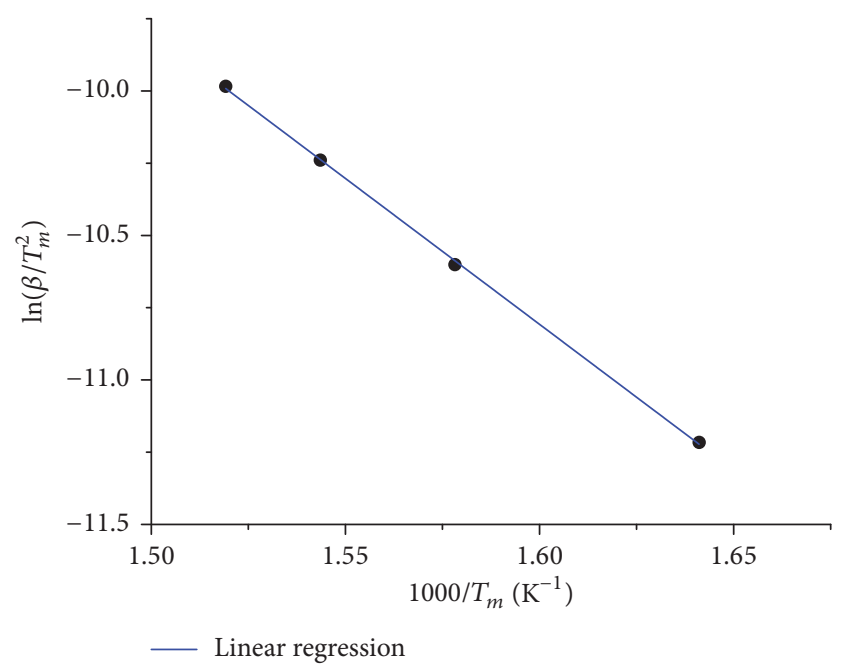

FIGURE 11: Kissinger plot for $7.2 \mathrm{wt} \% \mathrm{Fe} \_$Nitrate sample extracted from TPR traces measured during reduction $\left(5 \% \mathrm{H}_{2}\right.$ in $95 \%$ argon).

3.2.2. Method of Ozawa, Flynn, and Wall. A single apparent activation energy value resulting from the Kissinger method may not be sufficient for a detailed kinetic analysis of a solid-state reaction. Therefore, the isoconversional, modelindependent OFW method was applied for determining the evolution of the apparent activation energy of the ratedetermining step as function of reduction degree $\alpha[11,26-$ 28]. Reduction degree $\alpha$ traces were extracted by integration of the TPR traces measured at various heating rates $\beta$. First, temperatures $T_{\alpha, \beta}$ for defined reduction degrees $\alpha$ were determined from the experimental $\alpha$ traces at various heating rates. Temperatures $T_{\alpha, \beta}$ were determined for reduction degrees in the range of 0.1 and 0.8 , with $\Delta \alpha=0.1$. Second, decade logarithm of the heating rate as function of $1000 / T_{\alpha, \beta}$ for the different reduction degrees was calculated based on

$$
\log (\beta)=\log \left(\frac{A_{\alpha} E_{a, \alpha}}{g(\alpha) R}\right)-2.315-0.457 \frac{E_{a, \alpha}}{R T_{\alpha, \beta}},
$$

with heating rate $\beta$, preexponential (frequency) factor $A_{\alpha}$ at reduction degrees $\alpha$, apparent activation energy at reduction degrees $\alpha E_{a, \alpha}$, integral solid-state reaction model $g(\alpha)$, gas constant $R$, and temperatures $T_{\alpha, \beta}$. Figure 12 shows the resulting straight lines for heating rates of $5,10,15$, and $20 \mathrm{~K} / \mathrm{min}$ and various reduction degrees $\alpha$. Linear regression of the resulting straight lines resulted in apparent activation energy as a function of reduction degree $\alpha$. Because of $E_{a, \alpha} / R T_{\alpha, \beta}<$ 


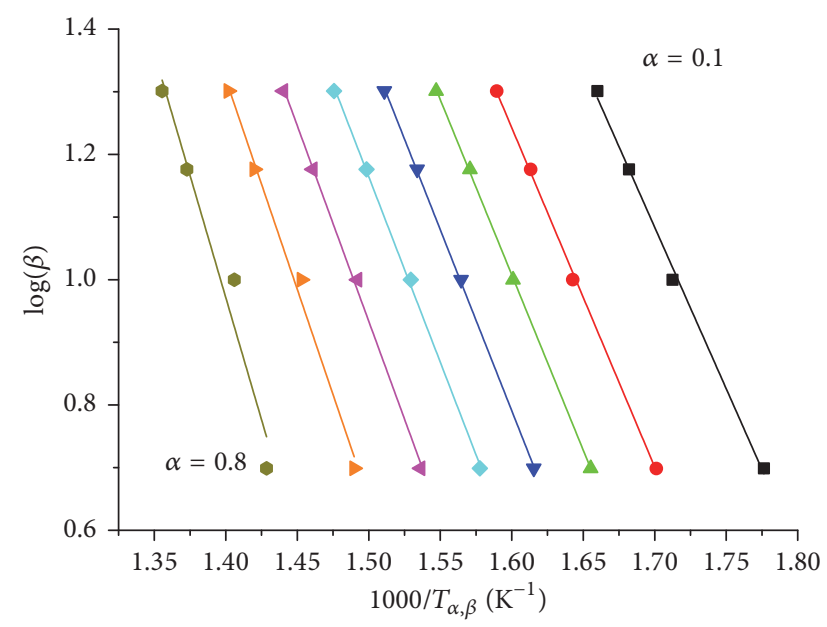

FIGURE 12: Logarithmic heating rate $\beta$ as function of reciprocal temperature for the reduction of $7.2 \mathrm{wt} \% \mathrm{Fe} \_$Nitrate in $5 \% \mathrm{H}_{2}$ in $95 \%$ argon and reduction degree range from 0.1 to 0.8 (OFW method).

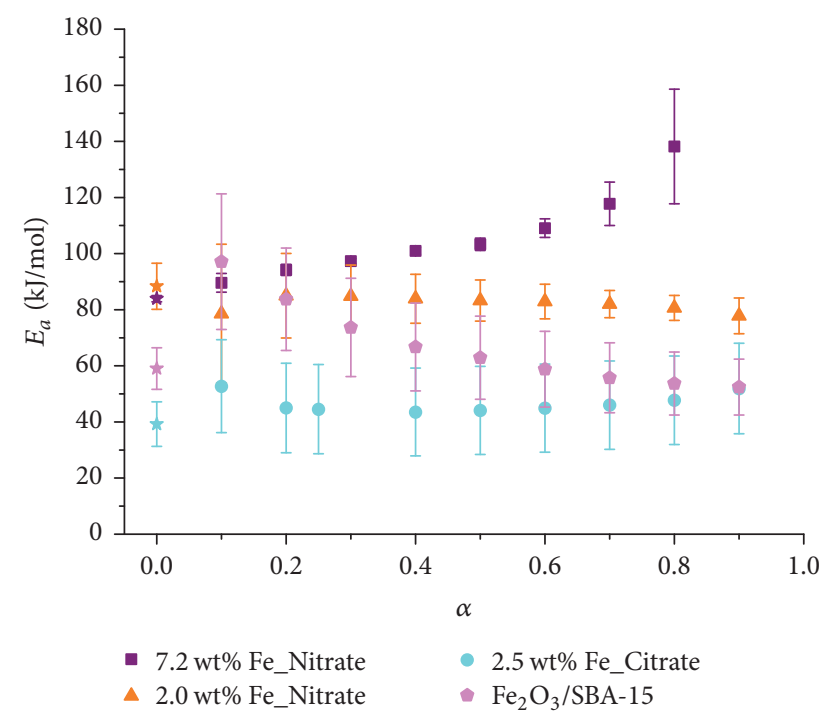

FIGURE 13: Apparent activation energy $E_{a}$ as function of reduction degree $\alpha$ for the reduction of $2.5 \mathrm{wt} \%$ Fe_Citrate (circles), $2.0 \mathrm{wt} \%$ $\mathrm{Fe} \_$Nitrate (triangles), $7.2 \mathrm{wt} \% \mathrm{Fe} \_$Nitrate (squares), and $\mathrm{Fe}_{2} \mathrm{O}_{3} / \mathrm{SBA}$ 15 (pentagons) in 5\% $\mathrm{H}_{2}$ in $95 \%$ argon (with Senum-Yang approximation). Apparent activation energies as determined from Kissinger method are indicated at $\alpha=0$ (stars).

20, the apparent activation energy was corrected according to Senum-Yang $[11,26]$. The resulting apparent activation energy together with the apparent activation energy determined by Kissinger method is depicted in Figure 13.

The apparent activation energy obtained from the Kissinger method for samples $2.5 \mathrm{wt} \%$ Fe_Citrate and $2.0 \mathrm{wt} \%$ Fe_Nitrate agreed with the apparent activation energy obtained from the OFW method (Figure 13). Furthermore, apparent activation energies $E_{a}(\alpha)$ of the lowest loaded citrate and nitrate samples were invariant in the $\alpha$ range within the error limits. Thus, a single-step reduction mechanism was assumed for the lowest loaded $\mathrm{Fe}_{x} \mathrm{O}_{y} / \mathrm{SBA}-15$ samples corresponding to the single reduction peak in the TPR profiles of these samples (Figures 8 and 9). Such a reaction mechanism is more similar to homogeneous kinetics than to complex heterogeneous kinetics. Compared to the lowest loaded citrate and nitrate samples, $7.2 \mathrm{wt} \% \mathrm{Fe} \_$Nitrate differed not only in the higher apparent activation energy values but also in the evolution of the apparent activation energy as function of reduction degree. The increase of the apparent activation energy may indicate a change in rate-determining step during a more complex reduction mechanism [29]. Moreover, such a more complex reduction mechanism correlated with the multistep TPR profile due to the presence of larger, weakly interacting iron species for sample $7.2 \mathrm{wt} \%$ Fe_Nitrate (Figure 9).

3.2.3. Coats-Redfern Method. In addition to the modelindependent Kissinger and OFW methods, the modeldependent Coats-Redfern [30] method provided a complementary analysis of nonisothermal kinetic data. Compared to a model-independent kinetic analysis, model-dependent analysis enables a more detailed characterization of the reaction mechanism. Here, resulting activation energies are based on assuming a suitable solid-state kinetic model. The Coats-Redfern method can be expressed by

$$
\ln \left(\frac{g(\alpha)}{T^{2}}\right)=\ln \left(\frac{A R}{\beta E_{a}}\left[1-\left(\frac{2 R T}{E_{a}}\right)\right]\right)-\frac{E_{a}}{R T},
$$

with the integral solid-state reaction model $g(\alpha)$, temperature $T$, heating rate $\beta$, apparent activation energy of ratedetermining step $E_{a}$, gas constant $R$, and preexponential (frequency) factor $A$. Plotting $\ln \left[g(\alpha) / T^{2}\right]$ as function of reciprocal temperature results in straight lines for suitable solid-state reaction models. Linear regression was conducted to determine the apparent activation energy. Here, only reaction models $g(\alpha)$ resulting in both suitable apparent activation energies and good linear regressions were selected for further analysis [30, 31].

For the reduction of $2.5 \mathrm{wt} \%$ Fe_Citrate, $2.0 \mathrm{wt} \%$ Fe_Nitrate, $7.2 \mathrm{wt} \%$ Fe_Nitrate, and the mechanical mixture $\mathrm{Fe}_{2} \mathrm{O}_{3}$ /SBA-15, reduction degree $\alpha$ curves were analyzed. Applied solid-state reaction models were nucleation models, including power law models (P) and Avrami-Erofeyev models (A), as well as the autocatalytic Prout-Tompkins model (B1). Furthermore, diffusion models (D), geometrical contraction models $(\mathrm{R})$, and reaction order-based models $(\mathrm{F})$ were tested [31]. D4, F1, A2, R2, and B1 solid-state reaction models revealed wide linear ranges by plotting $\ln \left[g(\alpha) / T^{2}\right]$ as function of reciprocal temperature for sample $2.5 \mathrm{wt} \%$ Fe_Citrate. Apparent activation energies for those models as obtained from the slope of the resulting straight lines are given in Table 5 .

Compared to the results of the Kissinger and OFW methods, apparent activation energies at different heating rates were significantly higher for the D4 model and significantly lower for the A2 model. Hence, D4 and A2 reaction models were not considered for further analysis. The B1 model (i.e., Prout-Tompkins model) yielded apparent activation energies similar to those obtained from Kissinger and OFW methods. 
TABLE 5: Apparent activation energy of reduction of sample $2.5 \mathrm{wt} \% \mathrm{Fe}$-Citrate in $5 \% \mathrm{H}_{2}$ at various heating rates depending on the applied solid-state kinetic reaction model.

\begin{tabular}{|c|c|c|c|c|c|}
\hline \multirow{2}{*}{ Heating rate $/ \mathrm{K} / \mathrm{min}$} & \multicolumn{5}{|c|}{$E_{a} / \mathrm{kJ} / \mathrm{mol}$} \\
\hline & B1 & $\mathrm{R} 2$ & $\mathrm{~A} 2$ & $\mathrm{D} 4$ & $\mathrm{~F} 1$ \\
\hline 5 & $43.8 \pm 0.2$ & $65.7 \pm 0.01$ & $32.6 \pm 0.03$ & $138.9 \pm 0.1$ & $75.0 \pm 0.1$ \\
\hline 10 & $41.6 \pm 0.3$ & $65.7 \pm 0.1$ & $31.9 \pm 0.03$ & $140.4 \pm 0.3$ & $73.7 \pm 0.1$ \\
\hline 20 & $54.6 \pm 0.3$ & $65.5 \pm 0.1$ & $35.7 \pm 0.1$ & $142.1 \pm 0.2$ & $77.9 \pm 0.3$ \\
\hline
\end{tabular}

However, the autocatalysis B1 model assumes that defects formed at the reaction interface during nuclei growth further catalyze and, hence, accelerate the reaction. This concept appears hardly applicable to $\mathrm{Fe}_{x} \mathrm{O}_{y} / \mathrm{SBA}-15$ samples with dispersed $\mathrm{Fe}$ species located in a nanostructured pore system. Therefore, the B1 model was also not further considered. Similar constraints hold for the R2 model. The R2 reaction model is described as geometrical contracting model in which nucleation occurs on the surface of the cylindrical crystal. Thus, the reaction rate is determined by the decreasing interface area between reactant and product phase during reaction [31]. Again, such a concept seems not applicable for small and dispersed iron species on the surface of porous support. Consequently, the F1 model was chosen as suitable reaction model for the lowest loaded citrate and nitrate samples, as well as for sample $7.2 \mathrm{wt} \% \mathrm{Fe} \_$Nitrate.

The first-order reaction model (F1, Mampel model) describes solid-state reactions with a large number of nucleation sites resulting in fast nucleation. Apparently, reduction of $\mathrm{Fe}_{x} \mathrm{O}_{y} / \mathrm{SBA}-15$ samples was inhibited neither by limited mobility of reactants nor by increasing product layer. Orderbased reaction models are the simplest solid-state reaction models similar to those used in homogeneous kinetics where ions in solution interact weakly with each other [31, 32]. Because the $\mathrm{Fe}$ (III) species of the $\mathrm{Fe}_{x} \mathrm{O}_{y} / \mathrm{SBA}-15$ samples constituted small and isolated nucleation sites, the F1 model can be readily applied to these samples.

For the mechanical mixture $\mathrm{Fe}_{2} \mathrm{O}_{3} / \mathrm{SBA}-15$, an R3 model was a suitable reaction model. The $\mathrm{R} 3$ model is denoted as contracting volume model with nucleation occurring rapidly on the surface of the particles. This reaction model was consistent with a mixture of $\mathrm{Fe}_{2} \mathrm{O}_{3}$ crystallites and SBA-15 material as obtained by conventional sample characterization.

3.2.4. JMAK Kinetics. In order to enable a geometrical description of the reduction reaction under nonisothermal conditions, Johnson-Mehl-Avrami-Kolmogorov (JMAK) kinetic analysis was applied $[33,34]$. JMAK kinetics are based on the following equation:

$$
\ln [-\ln (1-\alpha)]=-n \ln (\beta)-1.052 \frac{m E}{R T}+\text { Const., }
$$

with heating rate $\beta$, apparent activation energy of the ratedetermining step $E$, temperature $T$, gas constant $R$, reduction degree $\alpha$, topological dimension $m$, and Avrami exponent $n$. Plotting $\ln [-\ln (1-\alpha)]$ as function of reciprocal temperature at different heating rates resulted in straight lines (Figure 14(a)). From the slope of the resulting straight lines, the topological dimension $m$ can be determined. Here, the apparent activation energy obtained by the Kissinger method was inserted in (3). Based on (3), the Avrami exponent $n$ is derived according to

$$
-n=\left.\frac{d\{\ln [-\ln (1-\alpha)]\}}{d[\ln (\beta)]}\right|_{T},
$$

with Avrami exponent $n$, reduction degree $\alpha$, heating rate $\beta$, and temperature $T$. Thus, values of $\ln [-\ln (1-\alpha)]$ were calculated at fixed temperatures and plotted as function of $\ln (\beta)$. Temperature intervals were equidistant. The slopes of the resulting straight lines (Figure 14(b)) were used to determine the Avrami exponents. Plotting $\ln [-\ln (1-\alpha)]$ as function of reciprocal temperature did not afford straight lines for sample $2.5 \mathrm{wt} \% \mathrm{Fe} \_$Citrate. Therefore, JMAK kinetics were not applied to the data of this sample. Topological dimension and Avrami exponent as function of temperature and heating rate for sample $7.2 \mathrm{wt} \% \mathrm{Fe}$ Nitrate and $2.0 \mathrm{wt} \%$ $\mathrm{Fe} \_$Nitrate are depicted in Figures 15 and 16. Topological dimension and Avrami exponent for both samples were one. A topological dimension of one corresponded to linear and one-dimensional iron species in these nitrate samples. Onedimensionality was consistent with the iron species being in the pore system of SBA-15. At $n=m=1$, the reduction mechanism is governed by site saturation. Thus, at the beginning of the reduction, nucleation sites either already existed or were formed immediately.

The Coats-Redfern method identified the F1, Mampel, and solid-state kinetic reaction model being suitable to describe the kinetic data. The Mampel model is consistent with the assumption of site saturation. Moreover, the Mampel model represents an exception of the Avrami-Erofeyev model with an Avrami exponent of $n=1$. Hence, results from JMAK kinetic analysis and model-dependent Coats-Redfern method agreed well for the nitrate samples.

The mechanical mixture $\mathrm{Fe}_{2} \mathrm{O}_{3} / \mathrm{SBA}-15$ exhibited a higher topological dimension. Topological dimension as function of the heating rate ranged between 2 and 3 (Figure 17). This increase in topological dimension correlated with the presence of $\mathrm{Fe}_{2} \mathrm{O}_{3}$ crystallites in this sample. The mechanical mixture exhibited $\mathrm{Fe}_{2} \mathrm{O}_{3}$ crystallites mixed with the support material. Model-dependent Coats-Redfern method identified the geometrical contraction model R3 being a suitable reaction model. Therefore, three-dimensional reduction was compatible with a rapid nucleation on the $\mathrm{Fe}_{2} \mathrm{O}_{3}$ crystallites. Thus, for the mechanical mixture $\mathrm{Fe}_{2} \mathrm{O}_{3} / \mathrm{SBA}-15$, results from model-dependent Coats-Redfern analysis were confirmed by the JMAK analysis. 


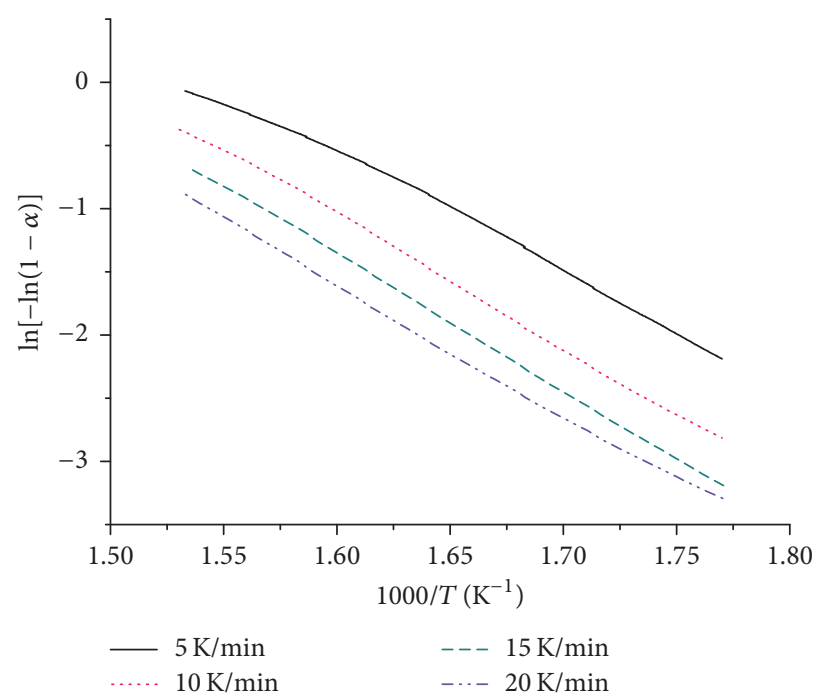

(a)

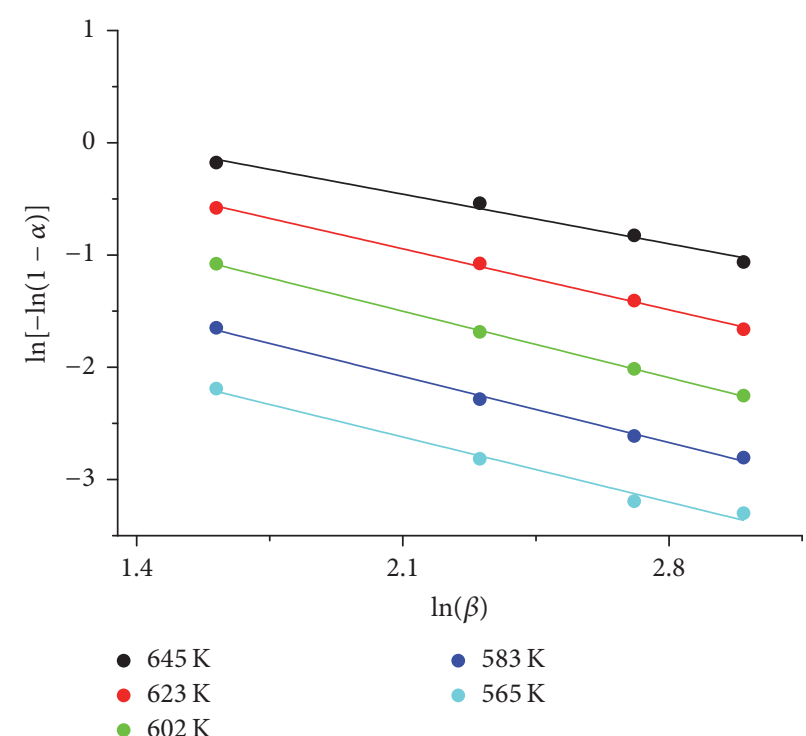

(b)

Figure 14: (a) $\ln [-\ln (1-\alpha)]$ as function of 1000/T according to JMAK kinetics for determining the topological dimension of the reduction of $7.2 \mathrm{wt} \% \mathrm{Fe}_{-}$Nitrate $\left(5 \% \mathrm{H}_{2}\right.$ in $95 \%$ argon). (b) $\ln [-\ln (1-\alpha)]$ as function of $\ln (\beta)$ according to JMAK kinetics in order to determine the Avrami exponent for sample $7.2 \mathrm{wt} \% \mathrm{Fe} \_$Nitrate.

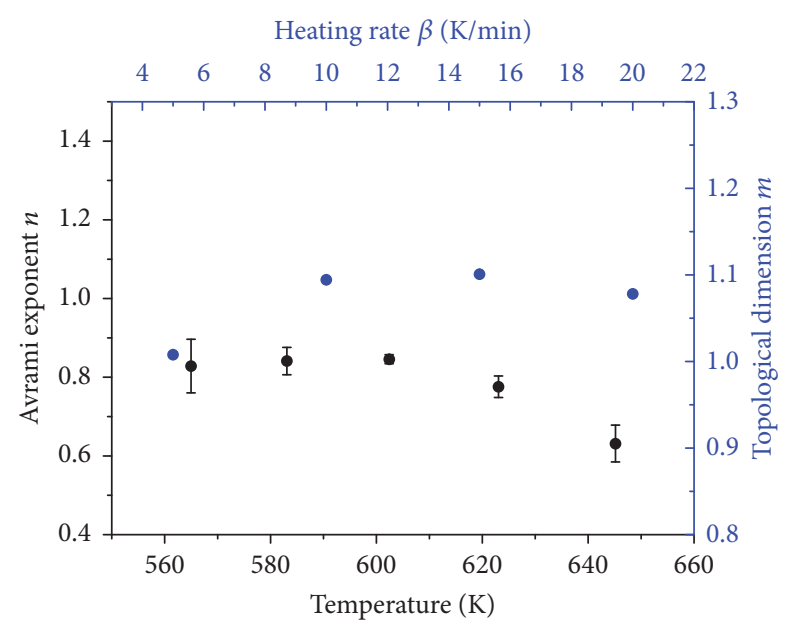

FIgURE 15: Topological dimension and Avrami exponent from JMAK kinetic analysis as function of temperature and heating rate for sample $7.2 \mathrm{wt} \%$ Fe_Nitrate.

\subsection{Correlation between Sample Characterization and Solid-} State Kinetic Analysis. Results from sample characterization agreed well with those from solid-state kinetic analysis of the $\mathrm{Fe}_{x} \mathrm{O}_{y} / \mathrm{SBA}-15$ samples. An increasing species size with increasing iron loading (DR-UV-Vis and Mössbauer spectroscopy) correlated with a decreasing apparent activation energy of reduction for the nitrate samples. Conversely, small iron species resulting from $\left(\mathrm{Fe}(\mathrm{III}), \mathrm{NH}_{4}\right)$-citrate precursor coincided with the lowest apparent activation energy for the reduction of $2.5 \mathrm{wt} \%$ Fe_Citrate. Sample characterization analysis methods identified the $\mathrm{Fe}$ (III) species as being isolated in the pore system of SBA-15 and interacting weakly with each other. Even for the higher loaded samples with

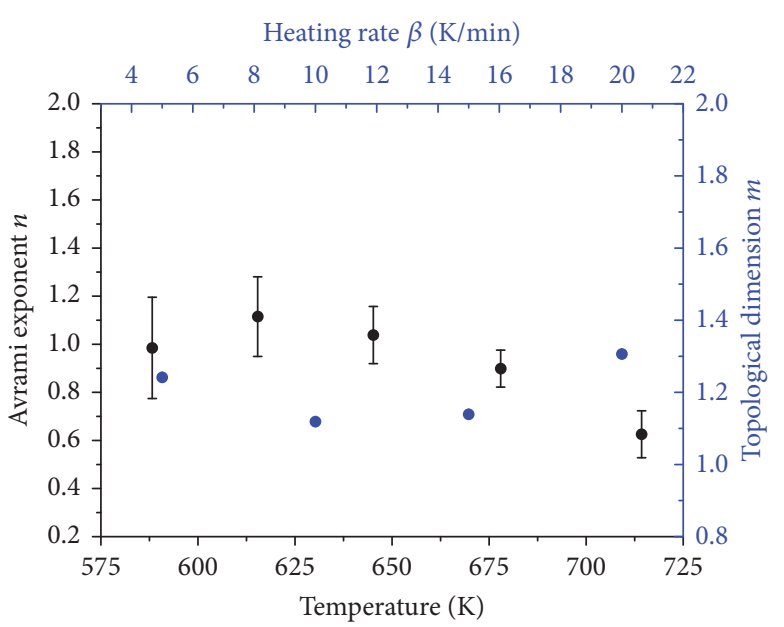

FIgURE 16: Topological dimension and Avrami exponent from JMAK kinetic analysis as function of temperature and heating rate for sample $2.0 \mathrm{wt} \%$ Fe_Nitrate.

more aggregated $\mathrm{Fe}_{m} \mathrm{O}_{n}$-nanoclusters, weakly interacting and well-dispersed Fe(III) species can be assumed. With respect to the kinetic analysis, iron species in the pores of SBA-15 react similar to isolated ions in a homogeneous solution. Accordingly, a first-order reaction model (Mampel model) was suited best to describe the similarity of the $\mathrm{Fe}_{x} \mathrm{O}_{y} / \mathrm{SBA}$ 15 samples and homogeneous systems. Additionally, JMAK kinetics were consistent with a one-dimensional reduction of Fe species localized in the pore system of SBA-15.

Not only for the $\mathrm{Fe}_{x} \mathrm{O}_{y} / \mathrm{SBA}-15$ samples but also for the mechanical mixture $\mathrm{Fe}_{2} \mathrm{O}_{3} / \mathrm{SBA}-15$, results from sample characterization agreed with those from kinetic analysis. According to JMAK analysis, the fraction of crystalline 


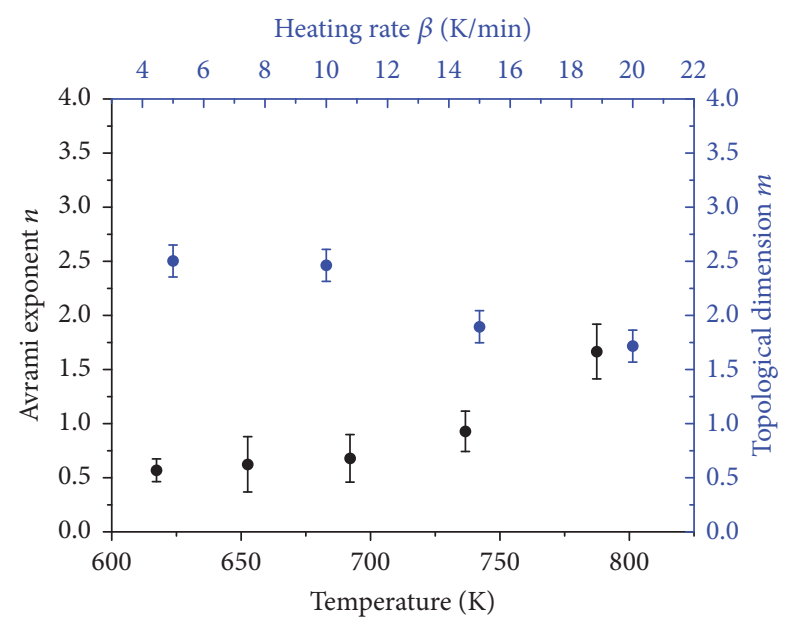

FIgUre 17: Topological dimension and Avrami exponent from JMAK kinetic analysis as function of temperature and heating rate for the mechanical mixture $\mathrm{Fe}_{2} \mathrm{O}_{3} /$ SBA-15.

$\mathrm{Fe}_{2} \mathrm{O}_{3}$ in $\mathrm{Fe}_{2} \mathrm{O}_{3} /$ SBA-15 as detected by XRD resulted in three-dimensional reduction kinetics. Hence, reduction was governed by rapid nucleation in the three-dimensional $\mathrm{Fe}_{2} \mathrm{O}_{3}$ crystallites. This was confirmed by the model-dependent analysis yielding a contracting volume model (R3) with rapid nucleation occurring on the surface of the $\mathrm{Fe}_{2} \mathrm{O}_{3}$ crystallites as suitable model for the rate-determining step in reduction.

Apparently, for both supported systems and the mechanical mixture, the results of conventional characterization and solid-state kinetic analysis corroborated each other. This showed that the concept of solid-state kinetic analysis (i.e., nonisothermal reaction conditions and model-dependent as well as model-independent methods) can be successfully applied to supported systems in addition to conventional bulk materials. Time- and temperature-dependent measurements such as TPR or TG/DTA are readily used in characterizing supported materials. Those techniques, however, yield little to no structural details of the supported species. Hence, solid-state kinetic analysis of the already available data can give additional information without additional experimental effort.

\section{Conclusions}

Iron oxides supported on SBA-15 were successfully synthesized using two different precursors (Fe(III)-nitrate and (Fe(III), $\mathrm{NH}_{4}$ )-citrate). Independent of the precursor, an increasing size of iron species correlated with an increasing iron loading. For all $\mathrm{Fe}_{x} \mathrm{O}_{y} / \mathrm{SBA}-15$ samples, a longrange ordering of iron oxidic species was excluded. Fe(III)nitrate precursor induced larger iron oxide species. Conversely, $\left(\mathrm{Fe}(\mathrm{III}), \mathrm{NH}_{4}\right)$-citrate precursor resulted in smaller iron species accompanied by more distinct smoothing of the SBA-15 surface. Temperature-programmed reduction of the $\mathrm{Fe}_{x} \mathrm{O}_{y} / \mathrm{SBA}-15$ samples revealed better reducibility of the nitrate samples compared to the citrate samples. The lowest loaded nitrate and citrate sample possessed a single-step reduction mechanism. Conversely, higher loaded $\mathrm{Fe}_{x} \mathrm{O}_{y} /$ SBA-15 samples revealed a more complex multistep reduction mechanism.

Solid-state kinetic analysis using model-dependent and model-independent methods demonstrated their applicability to dispersed iron species on a high surface area support material. Iron species obtained from the lowest loaded citrate precursor exhibited the lowest apparent activation energy. In the series of nitrate samples, a decreasing apparent activation energy and an increasing size of the iron species correlated with an increasing iron loading. Coats-Redfern method identified the Mampel reaction model as suitable to account for the rate-determining step in reduction. Moreover, site saturation, as suggested by the Mampel reaction model, was consistent with the results of JMAK analysis $(n=m=1)$.

\section{Conflicts of Interest}

The authors declare that there are no conflicts of interest regarding the publication of this paper.

\section{Acknowledgments}

M. Bröring and F. J. Litterst at the TU Braunschweig are acknowledged for providing access to the ${ }^{57} \mathrm{Fe}$ Mössbauer equipment. The authors are grateful to A. Müller and S. Schwarz for assistance during solid-state kinetics and $\mathrm{N}_{2}$ physisorption measurements, respectively, and to S. Selve at ZELMI (TU Berlin) for TEM measurements.

\section{References}

[1] U. S. Ozkan and R. B. Watson, "The structure-function relationships in selective oxidation reactions over metal oxides," Catalysis Today, vol. 100, no. 1-2, pp. 101-114, 2005.

[2] Y. Y. Sun, S. Walspurger, J.-P. Tessonnier, B. Louis, and J. Sommer, "Highly dispersed iron oxide nanoclusters supported on ordered mesoporous SBA-15: a very active catalyst for Friedel-Crafts alkylations," Applied Catalysis A: General, vol. 300, no. 1, pp. 1-7, 2006.

[3] Z. Gabelica, A. Charmot, R. Vataj, R. Soulimane, J. Barrault, and S. Valange, "Thermal degradation of iron chelate complexes adsorbed on mesoporous silica and alumina," Journal of Thermal Analysis and Calorimetry, vol. 95, no. 2, pp. 445-454, 2009.

[4] M. Oschatz, W. S. Lamme, J. Xie, A. I. Dugulan, and K. P. de Jong, "Ordered Mesoporous Materials as Supports for Stable Iron Catalysts in the Fischer-Tropsch Synthesis of Lower Olefins," ChemCatChem, vol. 8, no. 17, pp. 2846-2852, 2016.

[5] H. M. Torres Galvis, A. C. J. Koeken, J. H. Bitter et al., "Effect of precursor on the catalytic performance of supported iron catalysts for the Fischer-Tropsch synthesis of lower olefins," Catalysis Today, vol. 215, pp. 95-102, 2013.

[6] Y. Q. Jiang, K. F. Lin, Y. N. Zhang et al., "Fe-MCM-41 nanoparticles as versatile catalysts for phenol hydroxylation and for Friedel-Crafts alkylation," Applied Catalysis A: General, vol. 445-446, pp. 172-179, 2012.

[7] A. S. Al-Fatesh, A. H. Fakeeha, A. A. Ibrahim et al., "Iron Oxide Supported on Al2O3 Catalyst for Methane Decomposition 
Reaction: Effect of MgO Additive and Calcination Temperature," Journal of the Chinese Chemical Society, vol. 63, no. 2, pp. 205-212, 2016.

[8] J. C. Vedrine, G. Coudurier, and J.-M. M. Millet, "Molecular design of active sites in partial oxidation reactions on metallic oxides," Catalysis Today, vol. 33, no. 1-3, pp. 3-13, 1997.

[9] B. Grzybowska-Świerkosz, "Thirty years in selective oxidation on oxides: What have we learned?" Topics in Catalysis, vol. 1112, no. 1-4, pp. 23-42, 2000.

[10] D. Zhao, J. Feng, Q. Huo et al., "Triblock copolymer syntheses of mesoporous silica with periodic 50 to 300 angstrom pores," Science, vol. 279, no. 5350, pp. 548-552, 1998.

[11] A. Khawam and D. R. Flanagan, "Basics and applications of solid-state kinetics: a pharmaceutical perspective," Journal of Pharmaceutical Sciences, vol. 95, no. 3, pp. 472-498, 2006.

[12] S. Vyazovkin and C. A. Wight, "Kinetics in Solids," Annual Review of Physical Chemistry, vol. 48, no. 1, pp. 125-149, 1997.

[13] A. Khawam and D. R. Flanagan, "Role of isoconversional methods in varying activation energies of solid-state kinetics: I. isothermal kinetic studies," Thermochimica Acta, vol. 429, no. 1, pp. 93-102, 2005.

[14] S. Vyazovkin, "Kinetic concepts of thermally stimulated reactions in solids: A view from a historical perspective," International Reviews in Physical Chemistry, vol. 19, no. 1, pp. 45-60, 2000.

[15] M. Blume and J. A. Tjon, "Mössbauer spectra in a fluctuating environment," Physical Review A: Atomic, Molecular and Optical Physics, vol. 165, no. 2, pp. 446-456, 1968.

[16] P. Pfeifer, Y. J. Wu, M. W. Cole, and J. Krim, "Multilayer adsorption on a fractally rough surface," Physical Review Letters, vol. 62, no. 17, pp. 1997-2000, 1989.

[17] M. A. Smith and R. F. Lobo, "A fractal description of pore structure in block-copolymer templated mesoporous silicates," Microporous and Mesoporous Materials, vol. 131, no. 1-3, pp. 204209, 2010.

[18] R. S. Weber, "Effect of local structure on the UV-visible absorption edges of molybdenum oxide clusters and supported molybdenum oxides," Journal of Catalysis, vol. 151, no. 2, pp. 470-474, 1995.

[19] J. He, Y. Li, D. An, Q. Zhang, and Y. Wang, "Selective oxidation of methane to formaldehyde by oxygen over silica-supported iron catalysts," Journal of Natural Gas Chemistry, vol. 18, no. 3, pp. 288-294, 2009.

[20] L. A. Cano, M. V. Cagnoli, N. A. Fellenz et al., "Fischer-Tropsch synthesis. Influence of the crystal size of iron active species on the activity and selectivity," Applied Catalysis A: General, vol. 379, no. 1-2, pp. 105-110, 2010.

[21] F. Arena, G. Gatti, G. Martra et al., "Structure and reactivity in the selective oxidation of methane to formaldehyde of lowloaded $\mathrm{FeOx} / \mathrm{SiO} 2$ catalysts," Journal of Catalysis, vol. 231, no. 2 , pp. 365-380, 2005.

[22] W. Kündig, H. Bömmel, G. Constabaris, and R. H. Lindquist, "Some properties of supported small $\alpha$-Fe2O3 particles determined with the mössbauer effect," Physical Review A: Atomic, Molecular and Optical Physics, vol. 142, no. 2, pp. 327-333, 1966.

[23] J.-Y. Park, Y.-J. Lee, P. K. Khanna, K.-W. Jun, J. W. Bae, and Y. H. Kim, "Alumina-supported iron oxide nanoparticles as FischerTropsch catalysts: Effect of particle size of iron oxide," Journal of Molecular Catalysis A: Chemical, vol. 323, no. 1-2, pp. 84-90, 2010.
[24] T. Ressler, J. Wienold, R. E. Jentoft, O. Timpe, and T. Neisius, "Solid state kinetics of the oxidation of $\mathrm{MoO} 2$ investigated by time-resolved X-ray absorption spectroscopy," Solid State Communications, vol. 119, no. 3, pp. 169-174, 2001.

[25] H. E. Kissinger, "Reaction kinetics in differential thermal analysis," Analytical Chemistry, vol. 29, no. 11, pp. 1702-1706, 1957.

[26] B. Jankovic, "Kinetic analysis of the nonisothermal decomposition of potassium metabisulfite using the model-fitting and isoconversional (model-free) methods," Chemical Engineering Journal, vol. 139, no. 1, pp. 128-135, 2008.

[27] J. H. Flynn, "The isoconversional method for determination of energy of activation at constant heating rates - Corrections for the Doyle approximation," Journal of Thermal Analysis and Calorimetry, vol. 27, no. 1, pp. 95-102, 1983.

[28] T. J. Ozawa, "Kinetic analysis of derivative curves in thermal analysis," Journal of Thermal Analysis and Calorimetry, vol. 2, no. 3, pp. 301-324, 1970.

[29] M. Khachani, A. El Hamidi, M. Kacimi, M. Halim, and S. Arsalane, "Kinetic approach of multi-step thermal decomposition processes of iron(III) phosphate dihydrate FePO4.2H2O," Thermochimica Acta, vol. 610, pp. 29-36, 2015.

[30] A. W. Coats and J. P. Redfern, "Kinetic parameters from thermogravimetric data," Nature, vol. 201, no. 4914, pp. 68-69, 1964.

[31] A. Khawam and D. R. Flanagan, "Solid-state kinetic models: basics and mathematical fundamentals," The Journal of Physical Chemistry B, vol. 110, no. 35, pp. 17315-17328, 2006.

[32] A. J. Smith, L. O. Garciano, T. Tran, and M. S. Wainwright, "Structure and kinetics of leaching for the formation of skeletal (raney) cobalt catalysts," Industrial \& Engineering Chemistry Research, vol. 47, no. 5, pp. 1409-1415, 2008.

[33] E. Lorente, J. A. Peña, and J. Herguido, "Kinetic study of the redox process for separating and storing hydrogen: Oxidation stage and ageing of solid," International Journal of Hydrogen Energy, vol. 33, no. 2, pp. 615-626, 2008.

[34] K. Matusita, T. Komatsu, and R. Yokota, "Kinetics of nonisothermal crystallization process and activation energy for crystal growth in amorphous materials," Journal of Materials Science, vol. 19, no. 1, pp. 291-296, 1984. 

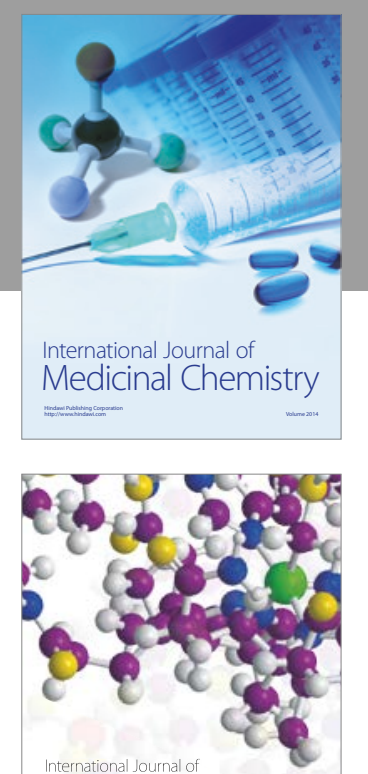

Carbohydrate Chemistry

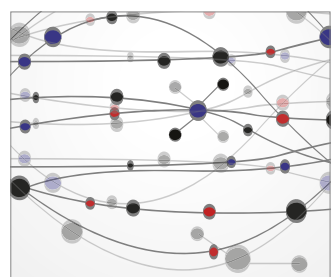

The Scientific World Journal
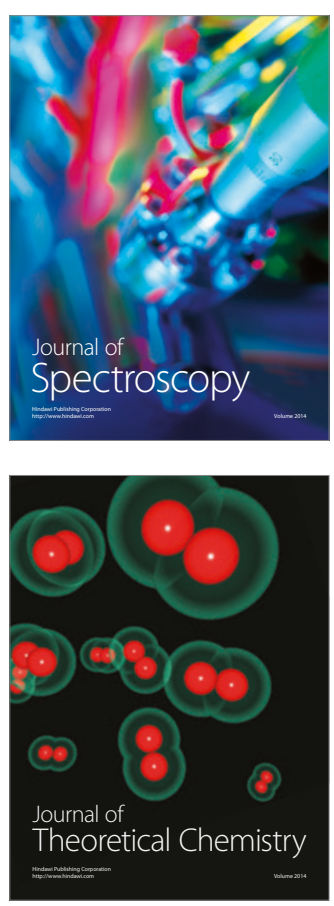
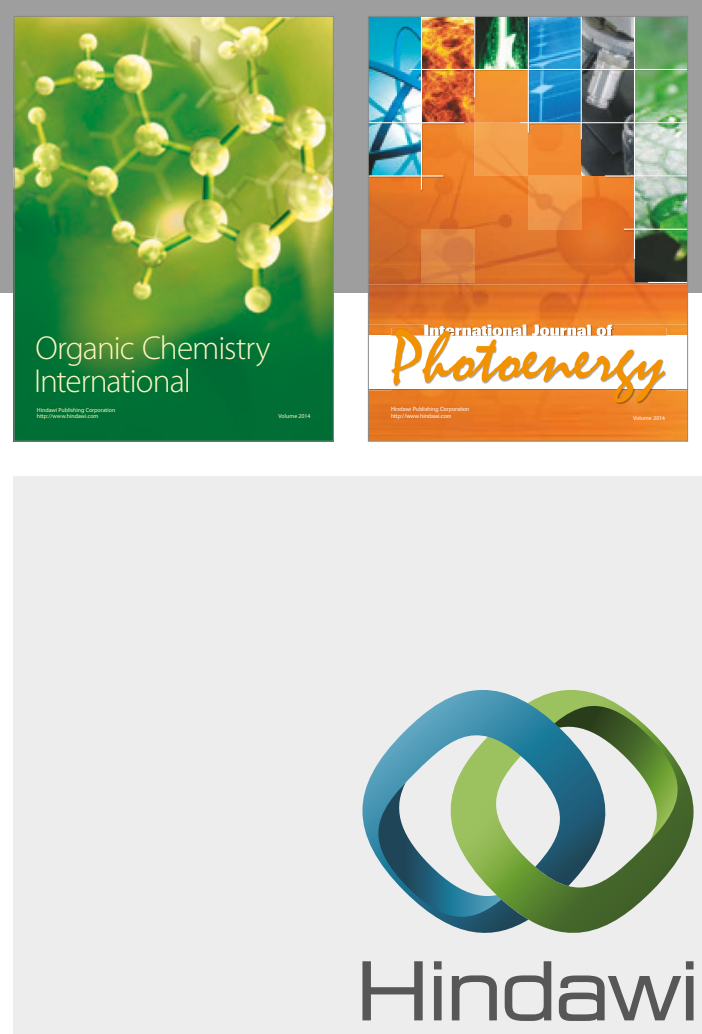

Submit your manuscripts at

https://www.hindawi.com

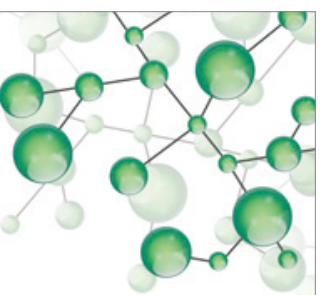

International Journal of

Inorganic Chemistry

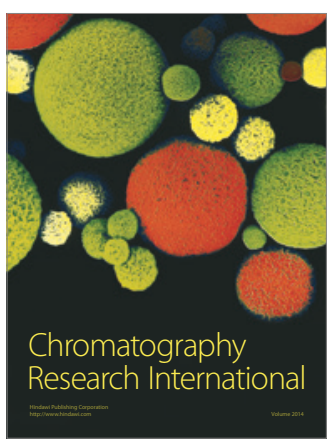

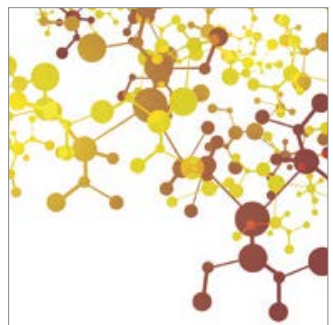

Applied Chemistry
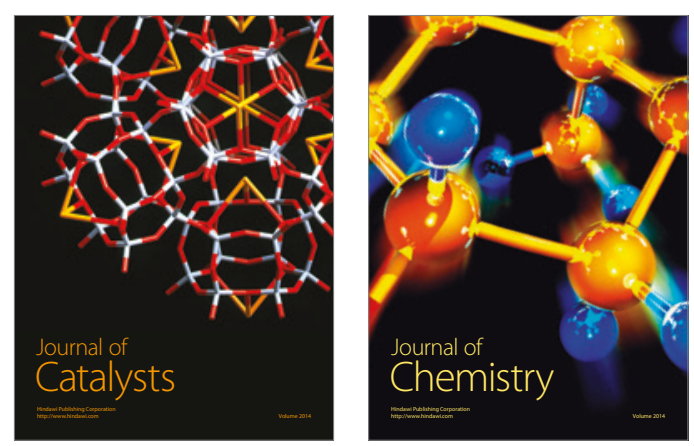
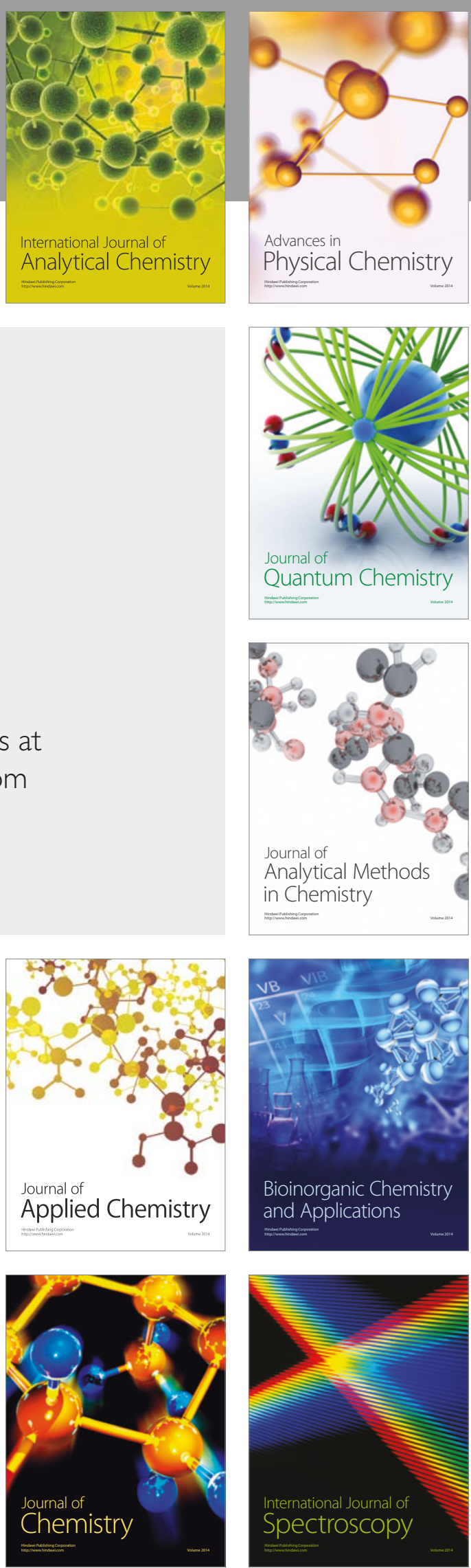